Article

\title{
Enhancing the Corrosion Protection of AA2024-T3 Alloy by Surface Treatments Based on Piperazine-Modified Hybrid Sol-Gel Films
}

\author{
Diógenes J. Carbonell ${ }^{1}$, Rodrigo Montoya ${ }^{2,3}$, Victoria J. Gelling ${ }^{4}$, Juan Carlos Galván ${ }^{2, *}$ [D and \\ Antonia Jiménez-Morales ${ }^{1, *(D)}$ \\ 1 Departamento de Ciencia e Ingeniería de Materiales e Ingeniería Química, IAAB, Universidad Carlos III de \\ Madrid, 28903 Leganés, Spain; diogenescarbonell@gmail.com \\ 2 Centro Nacional de Investigaciones Metalúrgicas (CENIM), Consejo Superior de Investigaciones \\ Científicas (CSIC), 28006 Madrid, Spain; rmontoyal@unam.mx \\ 3 Polo Universitario de Tecnología Avanzada (PUNTA), Universidad Nacional Autónoma de México (UNAM), \\ Apodaca 04510, NL, Mexico \\ 4 Department of Coatings and Polymeric Materials, North Dakota State University, Fargo, ND 58105, USA; \\ Victoria.Gelling@sherwin.com \\ * Correspondence: jcgalvan@cenim.csic.es (J.C.G.); toni@ing.uc3m.es (A.J.-M.); \\ Tel.: +34-915-538-900 (ext. 295/375) (J.C.G.)
}

Received: 14 March 2020; Accepted: 18 April 2020; Published: 21 April 2020

check for updates

\begin{abstract}
The aim of this study was to develop new chrome-free surface pretreatments for AA2024-T3 aluminum alloy. These pretreatments were based on hybrid organic-inorganic sol-gel thin films prepared from mixtures of $\gamma$-methacryloxypropyltrimethoxysilane (MAPTMS) and tetramethylorthosilicate (TMOS). Different MAPTMS/TMOS molar ratios were used for optimizing the physical-chemical characteristics of the sol-gel films. The formulation of a set of these sols was modified by incorporating piperazine (1,4-diazacyclohexane) as a corrosion inhibitor. The resulting sol-gel films were characterized by using Fourier transform infrared spectroscopy (FTIR), liquid-state ${ }^{29} \mathrm{Si}$ nuclear magnetic resonance spectroscopy $\left({ }^{29} \mathrm{Si}-\mathrm{NMR}\right)$ and viscosity measurements. The corrosion performance of the sol-gel films was analyzed by using electrochemical impedance spectroscopy (EIS) and local electrochemical impedance mapping (LEIM). The characterization techniques indicated that piperazine behaved as a catalyst for the condensation reaction during the formation of the MAPTMS/TMOS organopolysiloxane network and produces an increase of the crosslinking degree of the sol-gel films. EIS and LEIM results showed that piperazine is an effective corrosion inhibitor, which can be used to enhance the active corrosion protection performance of sol-gel films.
\end{abstract}

Keywords: AA2024-T3 aluminum alloys; hybrid sol-gel films; corrosion inhibitors; piperazine; electrochemical impedance spectroscopy; local electrochemical impedance mapping; active corrosion protection

\section{Introduction}

The AA2024-T3 aluminum alloy is widely used in aerospace, automotive and transportation industries generally due to their high strength-to-weight ratio, age-hardening, increased damage tolerance and durability, excellent fracture toughness and fatigue crack propagation and low manufacturing costs [1,2]. However, AA2024-T3 presents high contents of copper making it more susceptible to corrosion related to the distribution and composition of intermetallic particles [2,3]. These particles are considered the initiation sites for localized corrosion acting either as anodic or cathodic regions $[4,5]$. To prevent the development of these undesirable phenomena, it is necessary to 
apply remedial measures such as, for example, the use of chemical conversion pretreatments. In this context, numerous researchers are making a considerable effort to look for alternatives to chromate conversion coatings (CCCs) due to the carcinogenic effect of the hexavalent chromium used on these formulations [6,7]. One promising technique to develop eco-friendly and non-toxic coatings consists of applying films based on hybrid organopolysiloxane precursors as surface chemical conversion coatings [8-11]. The hybrid sol-gel method consists of a combination of hydrolysis and condensation processes of mixtures of organic and inorganic constituents, which makes possible the production of coatings with good flexibility, reduced defects and hydrophobic in nature, keeping the adhesion to the metal substrate and improving the compatibility with polymeric top-coatings [12-15].

For the past two decades, the application of sol-gel technologies for corrosion protection of metal surfaces has been revealed as a very attractive methodology, especially for the protection of AA2024 aluminum alloy [13-16]. Evidence that this topic continues to be of great interest within the scientific community is the large number of papers that are currently published [17-20].

Extensive lists of commercial alkoxysilane precursors used for sol-gel protective coatings can be found in the scientific literature [21,22]. One of these precursors is $\gamma$-methacryloxypropyltrimethoxysilane (MAPTMS). This research group has a wide background in the use of MAPTMS for the design and preparation of films of interest in advanced technologies and potential applications, such as membranes and electrodes for electrochemical devices, including also corrosion protection coating for zinc surfaces [23-25]. The idea now has been to use MAPTMS for designing novel protective coatings for AA2024 aluminum alloy.

An overview of the scientific literature shows that the MAPTMS has been widely used as a precursor for these purposes. The contributions of the research groups of Duran and Fedrizzi are remarkable [26-30]. It is noteworthy, for example, the contribution Rosero-Navarro et al. where they describe the development of a hybrid organic-inorganic coating based on mixtures of tetraethoxysilane (TEOS) and MAPTMS precursors and cerium nitrate as inhibitor [26]. The resulting coating showed interesting self-healing properties useful for the anticorrosive protection of AA2024 [26]. In a collaborative work between both groups, they describe the combination of permeability, provided by a MAPTMS hybrid matrix, with hardness and density of silica nanoparticles, which allowed obtaining a coating material where the diffusion of Ce ions occurred the same time such that an anticorrosive physical barrier was developed [27]. In more recent studies, Rodič et al. prepared transparent hybrid sol-gel coatings to serve as a barrier for corrosion protection of AA 2024 aluminum alloy. The coatings were synthesized using TEOS and MAPTMS [30]. These results indicate the need for optimization of chemical processes during synthesis, and identification of the chemical species responsible for coating degradation under aggressive conditions [30]. In the same context, but focused on more applicative aspects, is an above-mentioned study written by Hegde et al., describing the development of a functional sol-gel coatings based in mixtures of MAPTMS and zirconium (IV) propoxide for marine-based renewable energy applications [20].

A promising approach for improving the corrosion protection performance of the hybrid sol-gel coatings on metallic surfaces can be in the direction of incorporating amine crosslinkers into the organic-inorganic matrix [31,32]. Following this idea, some research groups focused their studies on the addition of different crosslinking agents based on piperazine derivatives in sol-gel matrices prepared from tetramethoxysilane (TMOS), $\gamma$-glycidoxypropyltrimethoxysilane (GPTMS) and polyamine crosslinking agents for increasing some features of the sol-gel matrix [33,34].

Piperazine is a secondary heterocyclic amine that consists of a six-membered ring containing two nitrogen atoms at opposite positions in the ring (Figure 1). Due to their specific properties as crosslinkers and curing agents, piperazine and its derivatives have been widely used in several research fields, such as in medicine and pharmacy [35-37] and $\mathrm{CO}_{2}$ capture technologies [38-40]. These additives have been also used in studies related to the preparation of coatings and polymers able to act as turn-on fluorescence sensing of ammonia gas [41], stimuli-responsive hydrogels sensitive to changes in $\mathrm{pH}$ and temperature [42], stimuli-responsive cationic hydrogels [43] and effective flame 
retardant for epoxy resins $[44,45]$. Piperazine has been also considered as an effective corrosion inhibitor for metals and alloys [46-48]. This behavior is due to the lone pairs of electrons of nitrogen atoms of piperazine interacting by adsorption or complexation with metal surfaces being able to inhibit the anodic and cathodic reaction [46]. It is foreseeable that this organic agent may also act as a corrosion inhibitor when introduced by physical entrapping or nano-encapsulation into the porous networks of sol-gel coatings.

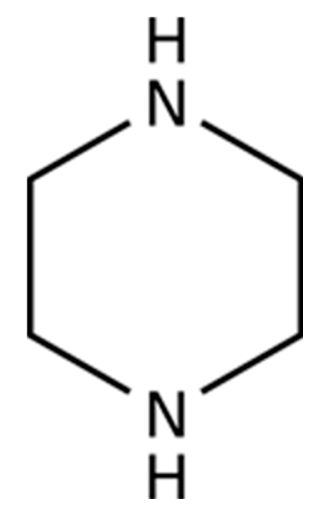

Figure 1. Molecular structure of the piperazine.

The aim of this research was to exploit the properties described above for using the piperazine as an additive that improves the corrosion protection behavior and barrier properties of tailored organic-inorganic hybrid films on AA2024-T3 aluminum alloy. The final objective is to design and develop novel sol-gel films as chemical conversion layers able to be a "green" alternative to efficient conventional surface pretreatments such as chromating or phosphating.

For such a purpose, some control parameters of the sol-gel process have been adjusted for tuning the structural properties and corrosion protection performance of the resulting hybrids films. In this way, sol-gel films with a variable molar ratio of two organopolysiloxane precursors (MAPTMS and TMOS) and different curing temperatures were tested. After the optimization study of the sol-gel formulations, some organic-inorganic hybrid matrices were modified by adding piperazine. Thus, it is expected that during the degradation process of the sol-gel films in contact with aqueous media, piperazine acts as a corrosion inhibitor hosted in the sol-gel network with the ability to be delivered to the defects and target sites of AA2024-T3 aluminum alloy where the film has failed.

\section{Materials and Methods}

\subsection{Sample Preparation}

The 2024-T3 aluminum alloy sheets ( $3 \mathrm{~mm}$ thick) were cut in small $150 \mathrm{~mm} \times 500 \mathrm{~mm}$ panels. The panels were grounded with silicon carbide paper 1000-grit, washed with distilled water and cleaned in an ultrasonic bath with acetone. Airflow was used to dry the panels.

\subsection{Unmodified Hybrid Sol-Gel Films}

The starting sols were prepared by co-hydrolysis and polycondensation of two organopolysiloxane precursors, methacryloxypropyltrimethoxysilane (MAPTMS) and tetramethylorthosilicate (TMOS), in 2:1, 3:1 and 4:1 molar ratios, which were labeled as 21, 31 and 41 samples, respectively. Ethanol and water were added with a (TMOS + MAPTMS)/water/ethanol molar ratio of $1 / 3 / 3$. All the precursors sourced from Sigma-Aldrich were used without any further purification. During hydrolysis and condensation, the mixture was magnetically stirred for $12 \mathrm{~h}$. at room temperature (ca. $20^{\circ} \mathrm{C}$ ). The hybrid sol-gel films were applied by dipping the AA2024-T3 samples into the sol-gel solution for $100 \mathrm{~s}$, followed by withdrawal (speed of $100 \mathrm{~mm} \mathrm{~min}^{-1}$ ). After the dip-film application, the samples were dried at $120^{\circ} \mathrm{C}$ for $2 \mathrm{~h}$. 


\subsection{Piperazine-Modified Hybrid Sol-Gel Films}

Piperazine (1,4-diazacyclohexane) was added to a set of 21 sol samples mixed with the water used for hydrolysis with the aim of increasing the crosslinking degree of the film and providing it with corrosion inhibition properties. The molar ratio of water/piperazine used was $1 / 1000$. The mixture of piperazine with the sol was stirred for $2 \mathrm{~h}$ and deposited by dip-coating using the same conditions above described for the piperazine-free sol-gel samples. Finally, after the deposition of the sols, the samples were dried at room temperature $\left(\mathrm{ca} .20^{\circ} \mathrm{C}\right)$ for $12 \mathrm{~h}$. The resulting samples were labeled with the code 21PIP.

It was forecasted that the addition of piperazine to the sol-gel mixture produced an increase of the sols' viscosity and led to the formation of thicker sol-gel layers. Taking this effect into account, for comparative purposes, different condensation thermal treatments were applied on a series of 21 piperazine-free sol-gel samples, until obtaining sol-gel films with similar thicknesses to those obtained with the formulations modified with piperazine. In concrete, the condensation time was variable, maintaining constant the condensation temperature at $60^{\circ} \mathrm{C}$. This series of piperazine-free sol-gel samples was labeled with the code 212 . Table 1 shows the processing conditions applied for obtaining the 212 and 21PIP samples.

Table 1. Experimental details used for preparation of the modified sol-gel films.

\begin{tabular}{ccc}
\hline Sample & $\mathbf{2 1 2}$ & 21PIP \\
\hline MAPTMS/TMOS molar ratio & $2: 1$ & $2: 1$ \\
Silane/ $\mathrm{H}_{2} \mathrm{O} /$ EtOH molar ratio & $1: 3: 3$ & $1: 3: 3$ \\
$\mathrm{H}_{2} \mathrm{O} /$ piperazine molar ratio & - & $1: 1000$ \\
Processing previous to dip-coating & Condensed $2 \mathrm{~h}$ at $60{ }^{\circ} \mathrm{C}$ & Stirred $2 \mathrm{~h}$ at room temperature $\left(\right.$ ca. $\left.20^{\circ} \mathrm{C}\right)$ \\
Curing temperature of the films & $120^{\circ} \mathrm{C}$ & Room temperature \\
Curing time of the films & $2 \mathrm{~h}$ & $12 \mathrm{~h}$ \\
\hline
\end{tabular}

\subsection{Coating Thickness}

A Philips XL30 scanning electron microscope (SEM) (Philips, Amsterdam, Netherlands) equipped with an energy dispersive X-ray (EDAX) spectrometer was used for measuring the thickness of the sol-gel films and localized chemical analyses of these samples. With this aim, the cross-section of a set of samples was stained with a gold layer for making SEM observation by using an acceleration voltage of $10 \mathrm{kV}$ and working distance of $10 \mathrm{~mm}$.

\subsection{Viscosity Measurements}

The viscosity of the sols was measured at room temperature $\left(\mathrm{ca} .20^{\circ} \mathrm{C}\right.$ ) and a shear rate of $10 \mathrm{~s}^{-1}$ in a Bohlin CVR rheometer (Bohlin Instruments Ltd., Cirencester, UK) equipped with a cone and plate geometry (plate: $60 \mathrm{~mm}$ diameter; cone: $40 \mathrm{~mm}$ diameter; cone angle: $4^{\circ}$; distance gap: $150 \mu \mathrm{m}$ ).

\subsection{FTIR Spectroscopy}

Fourier transform infrared spectra (FTIR) were collected using KBr disks with a droplet of the sol-gel hydrolyzed squeezed on the window. All the spectra were obtained at room temperature (ca. $20{ }^{\circ} \mathrm{C}$ ) by using a Perkin Elmer GX infrared spectrometer (PerkinElmer, Inc., Waltham, MA, USA) covering a wave number range of $4000-400 \mathrm{~cm}^{-1}$ with a resolution of $4 \mathrm{~cm}^{-1}$. A background was taken before and subtracted from the sample spectra.

\subsection{Liquid-State ${ }^{29}$ Si-NMR Spectra}

${ }^{29} \mathrm{Si}$ liquid-state nuclear magnetic resonance (NMR) spectra of the liquid samples were recorded at $79.49 \mathrm{MHz}$ in a Bruker AVANCE-400 Spectrometer (Bruker Corporation, Billerica, MA, USA). The external magnetic field was 9.4 T. The single-pulse NMR spectra were obtained after excitations 
with $\pi / 2$ pulse length of $6 \mu \mathrm{s}$. The deconvolutions of the NMR spectra were carried out with the Bruker WINFIT Program - (1994) Bruker Rep. 140:43-46 (Bruker Corporation, Billerica, MA, USA) for determining the different structures of different groups.

\subsection{Electrochemical Techniques}

Electrochemical impedance spectroscopy (EIS) measurements of sol-gel film/metal samples were made in $0.05 \mathrm{M} \mathrm{NaCl}$ aerated and quiescent aqueous solution at variable immersion time. A homemade electrochemical cell with a conventional three-electrode setup was used for the electrochemical measurements. The cell contained an $\mathrm{Ag} / \mathrm{AgCl} / \mathrm{KCl}$ (sat) as reference electrode ( $0.197 \mathrm{mV}$ vs. SHE), a platinum mesh as counter electrode and the tested sol-gel film/metal system as working electrode. This sol-gel coated AA2024-T3 electrode was clamped between a glass tube with an O-ring seal and a PTFE base in the horizontal position. All tested working electrodes were covered with porthole masks fabricated from vinyl 3M ${ }^{\mathrm{TM}}$ Electroplating Tape 470 (3M Centre, Binfield, Bracknell, UK) having a circular hole $\left(16 \mathrm{~mm}\right.$ diameter) to ensure a constant electrode area $\left(2.01 \mathrm{~cm}^{2}\right)$. The cell was placed into a Faraday cage to avoid the interference of external electromagnetic fields. The electrochemical measurements were made with a potentiostat/galvanostat instrument (Autolab-PGSTAT302N, Eco Chemie BV, Utrecht, Netherlands) equipped with a frequency response analyzer system FRA32M. Signal amplitudes of $\pm 10 \mathrm{mV}$ rms were applied. The range of measured frequencies extended from $10^{5} \mathrm{~Hz}$ to $10^{-2} \mathrm{~Hz}$, with a logarithmic sweep of 10 points per decade. The experiments were performed at open circuit potential (OCP), which was recorded prior to confirming the stability of the system. Electrochemical impedance experimental data were analyzed by using ZView ${ }^{\circledR}$ fitting and simulation software (Scribner Associates Inc., Southern Pines, NC, USA) and equivalent circuit models.

Local electrochemical impedance mapping (LEIM) measurements were performed with an M370 Scanning Electrochemical Workstation, manufactured by Uniscan Instruments (Buxton Derbyshire, UK), coupled to a PAR 273A potentiostat/galvanostat (EG\&G Princeton Applied Research, Princeton, NJ, USA) and a 1255 Solartron Frequency Response Analyzer (Solartron Analytical, Houston, TX, USA). The experimental setup for performing LEIM consisted of a 5-electrode configuration described in detail by Jorcin et al. [49]. A potentiometric bi-electrode U-LEIS370/1 (Bio-Logic Science Instruments) containing a platinized $\mathrm{Pt}$ tip and a platinized Pt ring was used as microprobe in this 5-electrode setup. The sol-gel coated metal sample was the working electrode. A low conductivity solution $(0.001 \mathrm{M} \mathrm{NaCl}$ aqueous solution, conductivity $\approx 90 \mu \mathrm{S} \mathrm{cm}^{-1}$ ) was used to optimize the resolution of the impedance measurement. LEIS were performed using signal amplitudes of $\pm 10 \mathrm{mV}$ and a frequency range from $40 \mathrm{kHz}$ to $10 \mathrm{~Hz}$. The experiments were carried out at open circuit potential, which was recorded for $10 \mathrm{~min}$ prior to confirming that the system was stable. After making frequency scans at constant probe positions in selected singular points, local electrochemical impedance mapping (LEIM) at constant frequency was recorded for analyzing the evolution of the metal/sol-gel films during immersion tests in the sodium chloride aqueous solution. LEIM were registered across rectangular areas of sol-gel films of $0.5 \mathrm{~mm} \times 5.0 \mathrm{~mm}$ and $3.0 \mathrm{~mm} \times 4.0 \mathrm{~mm}$ respectively, which contained in the center an artificial defect of diameter $0.055 \mathrm{~mm}$ made with a diamond tip. During the recording of the impedance maps, the distance between the tip of the microprobe and the sol-gel film surface was kept constant around $150 \mu \mathrm{m}$, which was monitored and adjusted with the help of a video camera. The constant frequencies selected to generate the impedance maps were $5000 \mathrm{~Hz}$ and $10 \mathrm{~Hz}$, respectively.

\section{Results and Discussion}

\subsection{Sol-Gel Films}

The co-hydrolysis and polycondensation of MAPTMS and TMOS in the selected experimental conditions produced a homogeneous polyorganosiloxane matrix without phase segregation. In this organo-inorganic network, it is possible to incorporate the piperazine giving gels with similar physical characteristics to those of the pristine gels. The presence of an organosilane as MAPTMS in the 
gel network is an essential requisite to provide a structure able to host piperazine. Moreover, the mechanical flexibility provided by the MAPTMS produces materials with the appropriate physical properties to allow processability into homogeneous films [50,51].

\subsection{Characterization of Unmodified Sol-Gel Films}

In order to estimate the thickness of unmodified (control) sol-gel films SEM/EDX analyses were carried out. Figure 2 presents a cross-section SEM image and EDX analysis of a 21 sol-gel film deposited on an AA2024-T3 substrate. These SEM/EDX analyses showed that the resulting sol-gel films were crack-free, continuous and homogeneous (Figure 2). Table 2 shows the thickness of the different sol-gel films tested calculated from these cross-section SEM pictures.

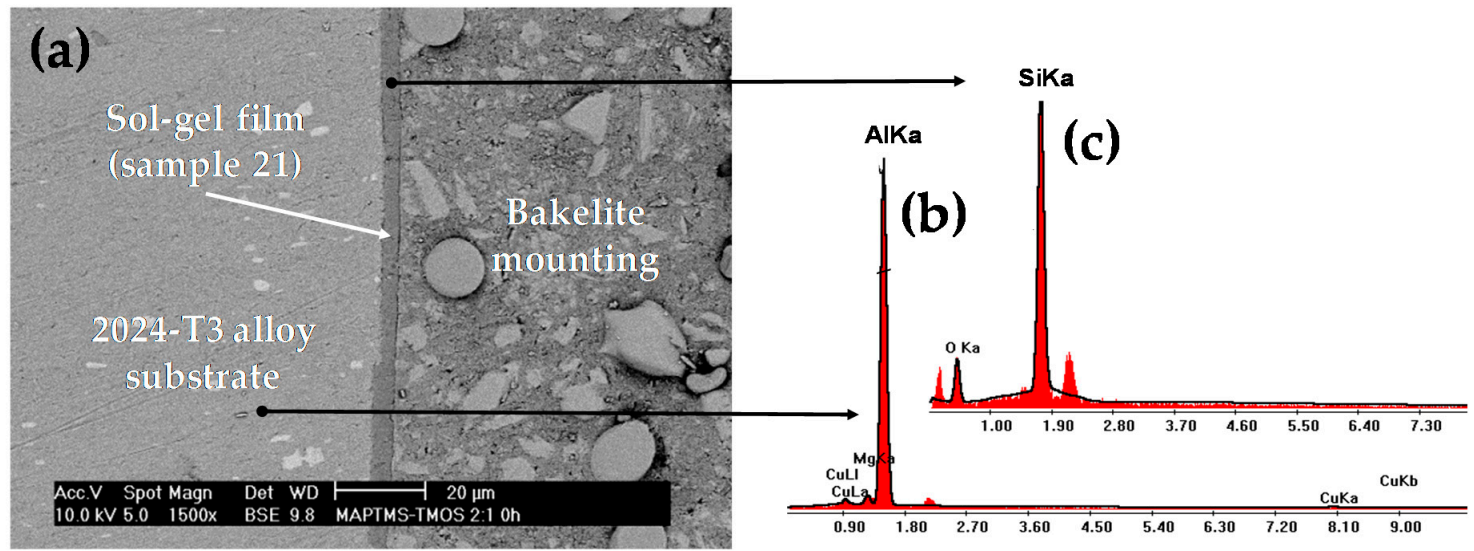

Figure 2. SEM/EDX analysis of a 21 sol-gel film applied on AA2024-T3 aluminum alloy: (a) SEM cross-section image (scale bar: $20 \mu \mathrm{m}$ ); (b) EDX spectrum obtained on the AA2024-T3 aluminum substrate and (c) EDX spectrum obtained on a zone of the sol-gel films.

Table 2. Viscosity and thickness values of the different control sol-gel films tested.

\begin{tabular}{cccc}
\hline Sample & $\mathbf{2 1}$ & $\mathbf{3 1}$ & $\mathbf{4 1}$ \\
\hline Viscosity $(\mathbf{m P a} \cdot \mathbf{s})$ & $5.97-6.96$ & $5.06-6.33$ & $5.48-6.39$ \\
Thickness $(\boldsymbol{\mu m})$ & $2.78 \pm 0.60$ & $2.43 \pm 0.67$ & $2.23 \pm 0.95$ \\
\hline
\end{tabular}

The rheological behavior was evaluated on freshly samples after $12 \mathrm{~h}$ of stirring and just before applying the sols on the AA2024-T3 substrate. Table 2 shows the viscosity values obtained for the different sols tested in the first step of this study (i.e., 21, 31 and 41 samples, respectively).

IR spectroscopy was applied to gain insight into the development of an organic-inorganic network and identify functional groups of hybrid films. The visible bands observed in the FTIR spectra at 1085 and $980 \mathrm{~cm}^{-1}$ are attributed to stretching vibrations of $\mathrm{Si}-\mathrm{O}-\mathrm{Si}$ bonds (Figure 3). These $\mathrm{Si}-\mathrm{O}-\mathrm{Si}$ bonds indicate that after $12 \mathrm{~h}$ of hydrolysis the process of condensation has already taken place, driving to the formation of a siloxane network. A broad band at $3420 \mathrm{~cm}^{-1}$ is also remarkable, which is assigned to $\mathrm{Si}-\mathrm{OH}$ formed through hydrolysis. A Si-OH stretching is also visible at $939 \mathrm{~cm}^{-1}$. After $12 \mathrm{~h}$, all the 21, 31 and 41 sol-gel samples showed similar performance and they were completely hydrolyzed, as shown in the FTIR spectra in Figure 3. These results agree with those reported in previous studies, where the authors showed results on a comprehensive study of the hydrolysis and condensation reactions of hybrid sol-gel materials of the same composition as sample 41 [51]. 


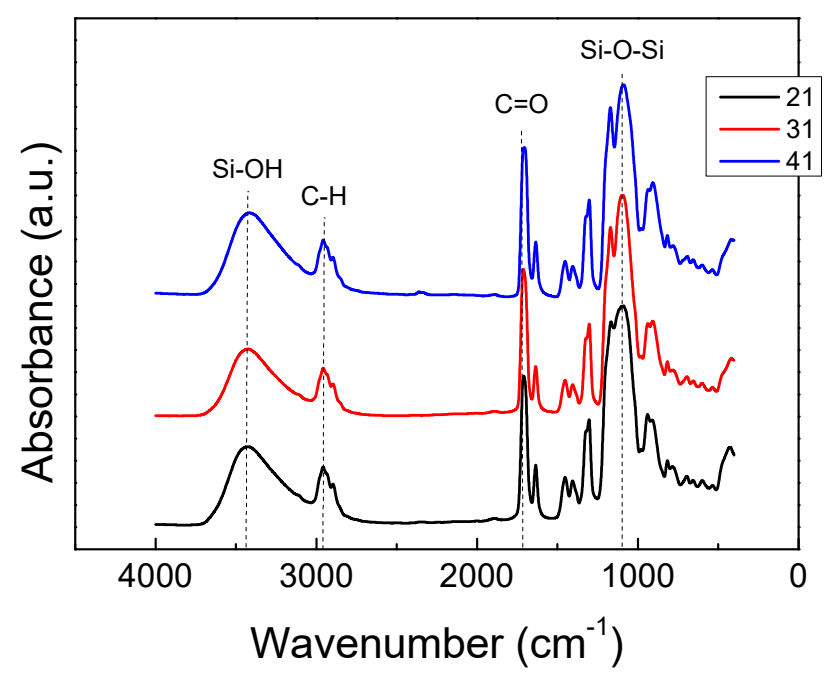

Figure 3. FTIR spectra obtained for $\gamma$-methacryloxypropyltrimethoxysilane (MAPTMS)/ tetramethylorthosilicate (TMOS) mixtures in the $\mathrm{EtOH} / \mathrm{H}_{2} \mathrm{O}$ solvent system for 21, 31 and 41 samples after $12 \mathrm{~h}$ of hydrolysis.

Figure 4 shows liquid-state ${ }^{29} \mathrm{Si}-\mathrm{NMR}$ spectra obtained for the samples tested. Signals of both $\mathrm{T}^{\mathrm{n}}$ and $\mathrm{Q}^{\mathrm{n}}$ species units identified for 21 samples were identified. The degree of condensation of the silanol groups is a function of its nearest neighbors. Referring to the literature $\mathrm{T}^{1}, \mathrm{~T}^{2}$ and $\mathrm{T}^{3}$ species $(-49,-58,-66 \mathrm{ppm})$ can be assigned to non-3D networks while chains containing $\mathrm{Q}^{2}, \mathrm{Q}^{3}$ and $\mathrm{Q}^{4}$ species $(-91,-100,-109 \mathrm{ppm})$ to can be ascribed to 3D networks [51-53]. It can be observed in Figure 4 that the $\mathrm{T}^{3}$ signal is less intense than those corresponding to $\mathrm{Si}$ atoms in $\mathrm{T}^{2}$ and $\mathrm{T}^{1}$ environments indicating that the organopolysiloxane matrix had a low degree of crosslinking. Figure 4 shows not just the assignments for different groups identified in MAPTMS-TMOS/ $\mathrm{H}_{2} \mathrm{O} / \mathrm{EtOH}$ system but also the fitting results for sol-gel sample 21.

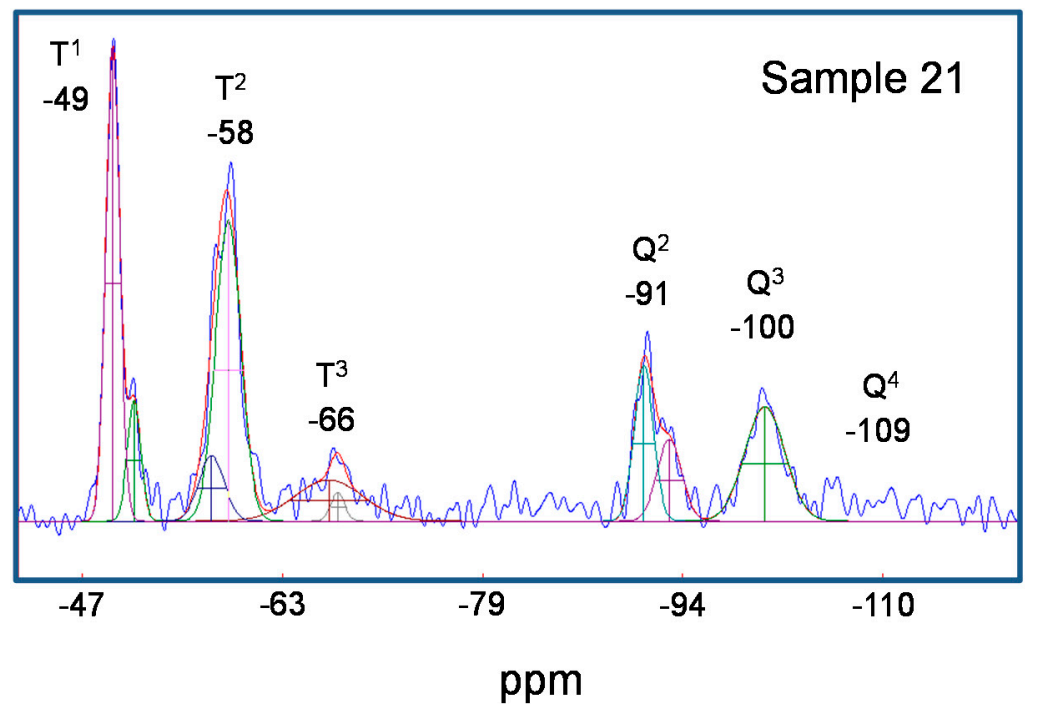

Figure 4. ${ }^{29}$ Si-NMR spectra showing the different $\mathrm{T}$ and $\mathrm{Q}$ units identified for 21 samples.

Figure 5 shows the relative proportion (\%) of different $\mathrm{T}$ and $\mathrm{Q}$ units identified by ${ }^{29} \mathrm{Si}-\mathrm{NMR}$ spectroscopy for 21, 31 and 41 samples. As expected, it can be seen from Figure 5 that the relative proportions of $\mathrm{T}$ units, associated with the polymerization of the MAPTMS precursor, is much higher than for the $\mathrm{Q}$ signals, which are associated with the TMOS condensation. This is because, in the molar 
ratio used in all the formulations tested, the added amount of the precursor MAPTMS against the TMOS always prevails.

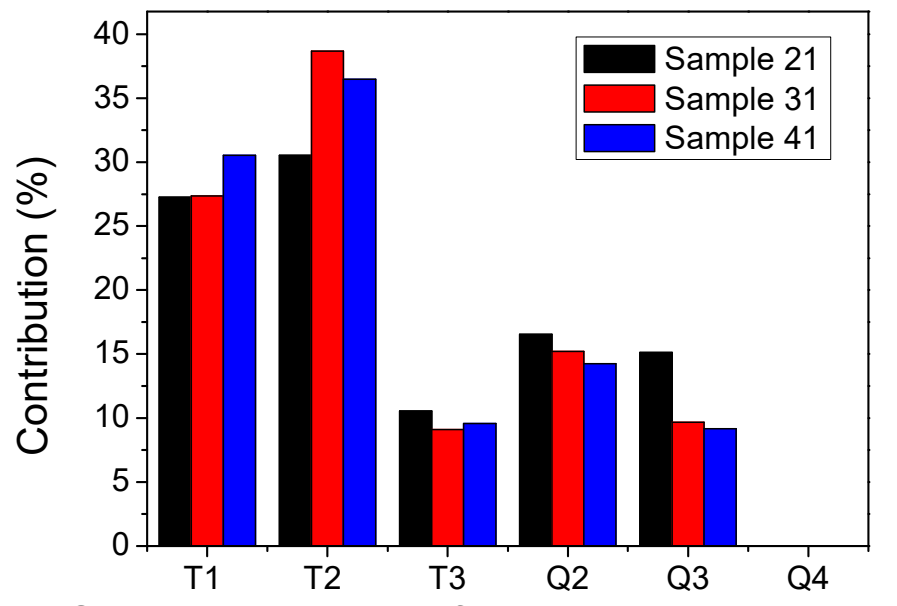

Silicon species identified in the sol-gel coatings

Figure 5. Relative proportion (\%) of different T-type and Q-type silicon units identified by ${ }^{29} \mathrm{Si}-\mathrm{NMR}$ spectroscopy for 21,31 and 41 samples.

A decreasing addition of TMOS precursor produces a decrease in the relative proportion of $Q^{2}$ and $\mathrm{Q}^{3}$ units. The most important change was observed in the contribution of the $\mathrm{Q}^{3}$ signal. In any case, the sol-gel matrix structure is not well crosslinked and no $Q^{4}$ specimens were detected in any of the 21,31 and 41 samples tested.

\subsection{Characterization of Piperazine-Modified Sol-Gel Samples}

Table 3 shows the viscosity and thickness values of the 212 and 212P samples were significantly higher than those obtained for piperazine-free control formulations (Table 2). As expected, the addition of piperazine to the organosilane mixture produced an increase in both the viscosity of the sols and the thickness of the resulting sol-gel films. Thus, the viscosity of the piperazine-modified sols reached values comprised between 9.83 and $10.8 \mathrm{mPa} \cdot \mathrm{s}$, while the thicknesses of the sol-gel films produced with these formulations were within the $9.11 \pm 1.43 \mu \mathrm{m}$ range.

Table 3. Viscosity and thickness values of the 212 and 212P samples.

\begin{tabular}{ccc}
\hline Sample & 212 & 21PIP \\
\hline Viscosity $(\mathbf{m P a} \cdot \mathbf{s})$ & $8.10-8.75$ & $9.83-10.80$ \\
Thickness $(\mu \mathrm{m})$ & $10.37 \pm 1.83$ & $9.11 \pm 1.43$ \\
\hline
\end{tabular}

For this reason and at comparative purposes, a special effort was devoted to achieving piperazine-free films that had thicknesses comparable to those obtained with coatings modified with this additive. In this way, typical iterative methods that are usually applied in crystalline/molecular engineering or nanoarchitectonics have had to apply in this research [23,54]. These technologies are specifically used for the design, preparation, characterization and study of the properties of the materials with a view to their applications, until the searched predetermined behavior is optimized [23]. Following these concepts, different parameters were changed in the synthesis process of the sol-gel films based on the formulations MAPTMS/TMOS of molar ratio = 2:1 (Samples 212), until obtaining films with the thickness desired. Finally changing the conditions of the condensation treatment by maintaining a constant temperature but varying the treatment time, piperazine-free films with thicknesses of $10.37 \pm 1.83 \mu \mathrm{m}$ were obtained, for a condensation treatment of $60^{\circ} \mathrm{C}$ and $2 \mathrm{~h}$ (Table 1 ). 
Figure 6 shows cross-section SEM images of 212 and 21PIP sol-gel films applied on AA2024-T3 aluminum alloys. These SEM images were used for estimating the thicknesses of the films shown in Table 3.
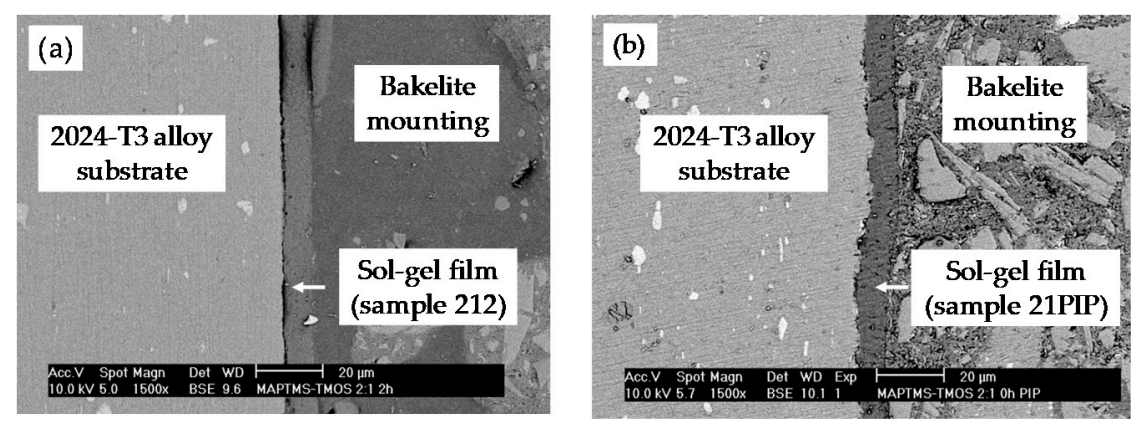

Figure 6. Cross-section SEM images of sol-gel films applied on AA2024-T3 aluminum alloy: (a) 212 sample and (b) 21PIP sample (scale bar: $20 \mu \mathrm{m}$ ).

Wood and Vreugdenhil et al. reported that piperazine derivatives were effective crosslinkers for a tetramethoxysilane/glycidoxypropyltrimethoxysilane (TMOS/GPTMS) binary sol-gel system [33,34]. FTIR spectra of such a sol-gel system evidenced that the epoxide ring of the GPTMS precursor opened the crosslinking reaction. This effect has been ascribed to the disappearance of the peaks associated with the epoxide ring due to the interaction of that system with the crosslinker agent [31]. In contrast, the FTIR spectra obtained now for the MAPTMS/TMOS organic-inorganic matrix incorporating piperazine show there was not any interaction between this MAPTMS/TMOS network and the heterocyclic compound incorporated. FTIR revealed that no changes were produced in the sol-gel network after adding piperazine to the sols and neither its condensation time (Figure 7). Therefore, it can deduce that in these MAPTMS/TMOS sol-gel systems the piperazine is not acting as a crosslinker agent but probably as a catalyst for the condensation reaction as shown also in the ${ }^{29} \mathrm{Si}-\mathrm{NMR}$ results which are discussed below. Some authors have already described the catalytic activity of piperazine bound to silica surfaces [55].

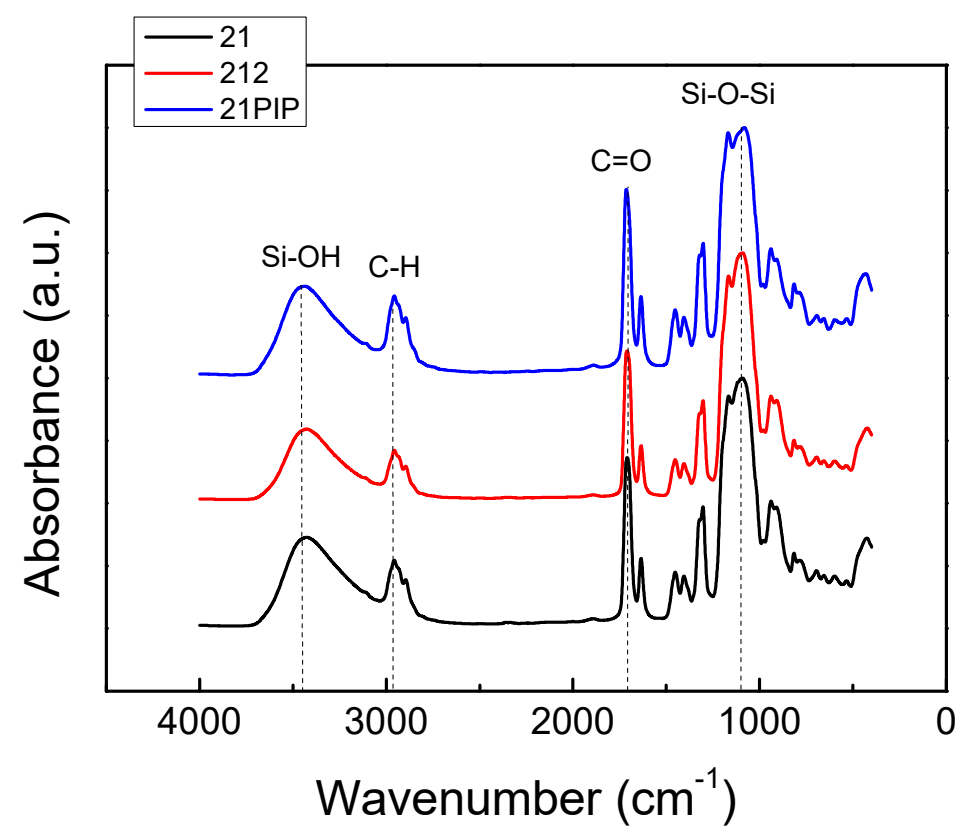

Figure 7. FTIR spectra obtained for 21, 212 and 21PIP samples after 12h of hydrolysis. 
The NMR spectra presented in Figure 8 show the WINFIT ${ }^{\circledR}$ adjustment on 212 and 21PIP samples demonstrating clearly the changes of the sol-gel after the addition of the piperazine decreasing the contribution of the groups $\mathrm{T}^{1}, \mathrm{~T}^{2}$ and $\mathrm{Q}^{2}$ and an increasing of the more crosslinked $\mathrm{T}^{3}$ group and also the disappearing of $\mathrm{Q}^{2}$ and the appearing of the $\mathrm{Q}^{4}$ group responsible of the most $3 \mathrm{D}$ dense structure.
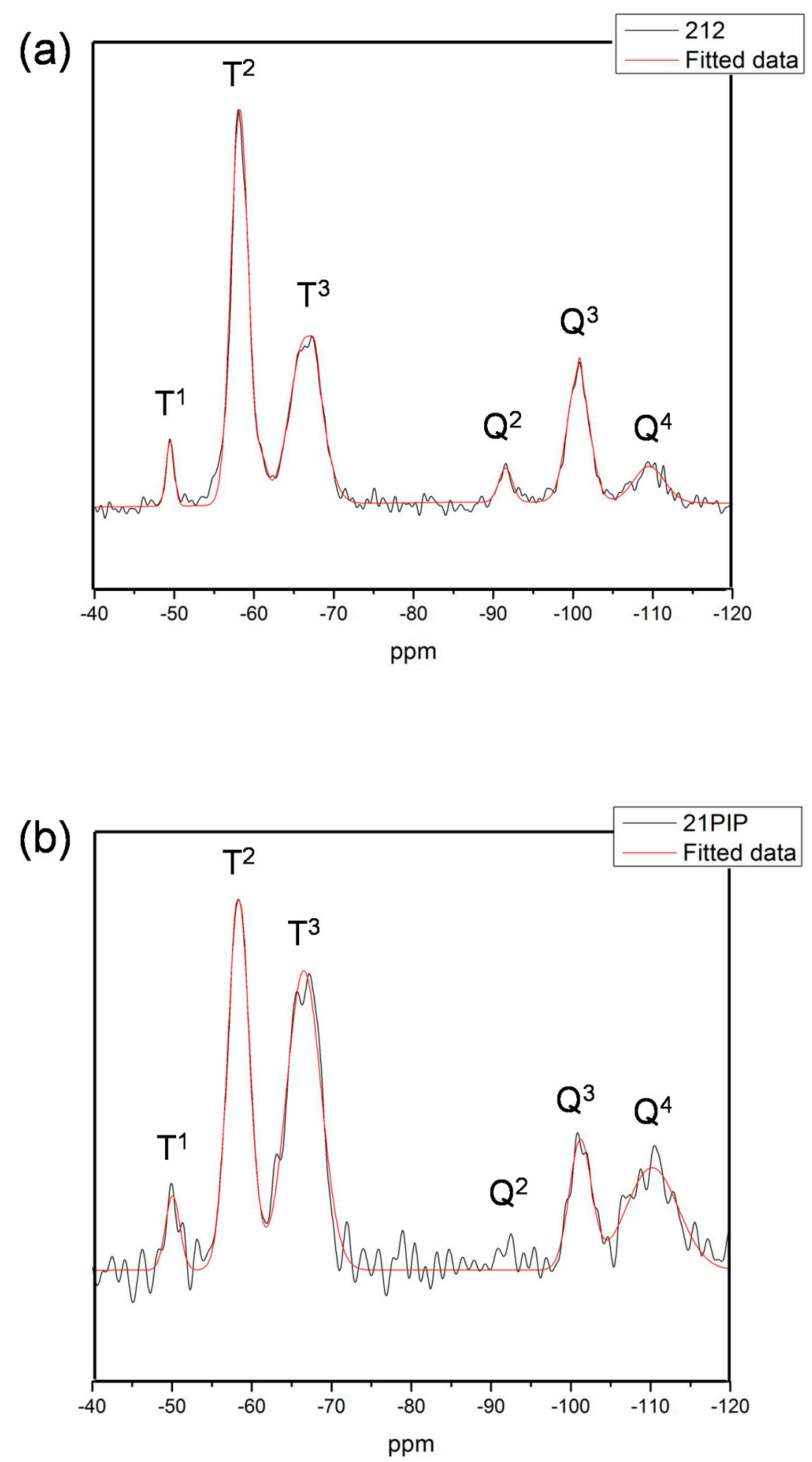

Figure 8. ${ }^{29} \mathrm{Si}-\mathrm{NMR}$ spectra and the different $\mathrm{Q}$ and $\mathrm{T}$ groups identified from the spectra in the 212 (a) and 21PIP (b) samples. 
Comparing the relative proportions of the structures of $\mathrm{T}$ and $\mathrm{Q}$ groups in the different tested samples (i.e., 21, 212 and 21PIP samples) clearly a more reticulated structure is observed in the 21PIP sample (Figure 9). Three-dimensional (3D) network is expected due to the increase of the $\mathrm{T}^{3}, \mathrm{Q}^{3}$ and $\mathrm{Q}^{4}$.

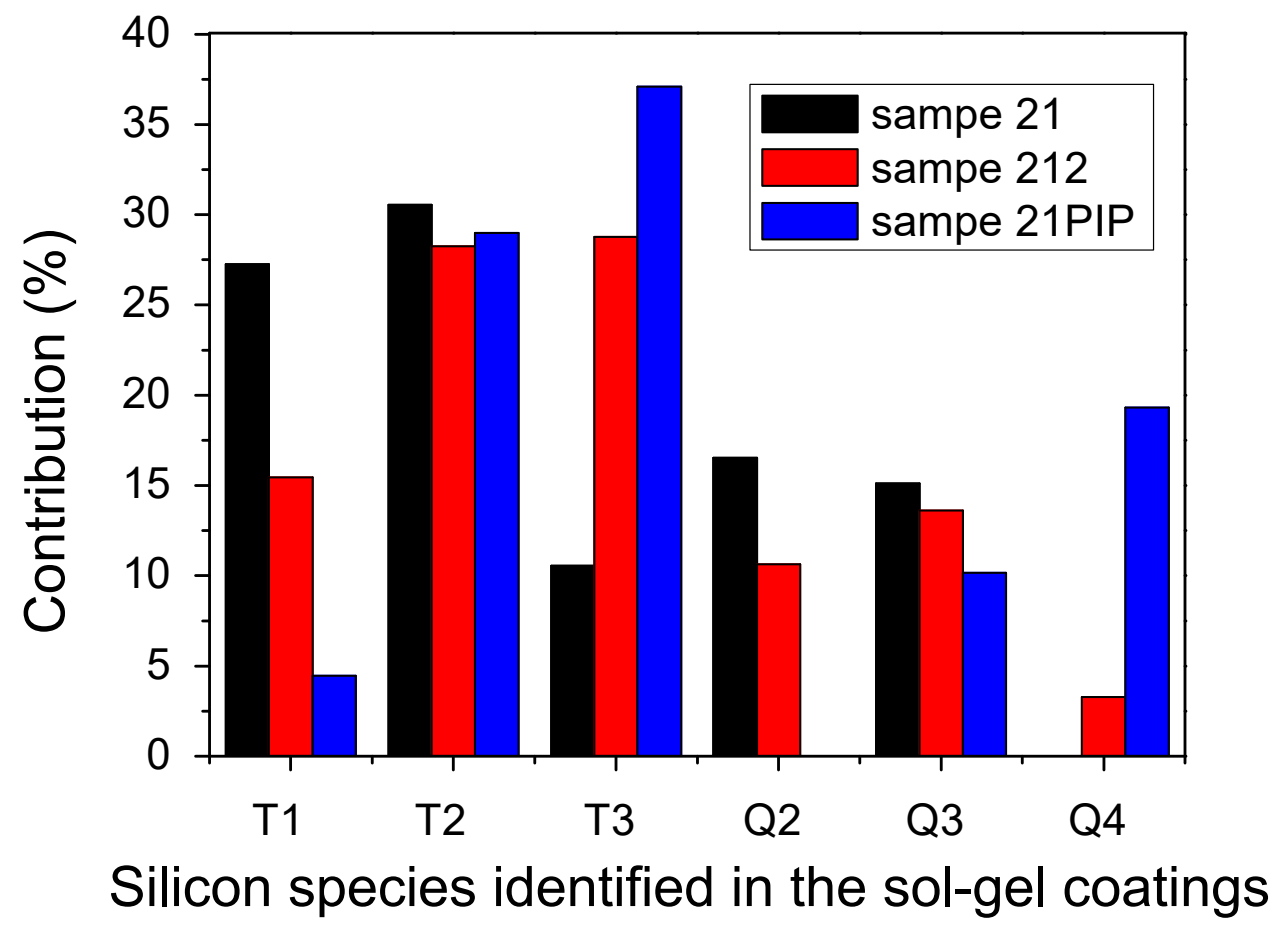

Figure 9. Relative proportions (\%) of different $\mathrm{T}$ and $\mathrm{Q}$ silicon units identified by ${ }^{29} \mathrm{Si}-\mathrm{NMR}$ spectroscopy for 21 and 212 and 21PIP samples.

\subsection{EIS Measurements on Unmodified Sol-Gel Films}

Figures 10 and 11 show the evolution of the Nyquist and Bode plots for AA2024-T3 alloys coated with 21, 31 and 41 sol-gel films during immersion tests in $0.05 \mathrm{M} \mathrm{NaCl}$ aqueous solution (from $1 \mathrm{~h}$ to $72 \mathrm{~h}$ ). The recordings in the left column of Figure 10 show the impedance response as Nyquist plots corresponding to all the frequencies ranges studied, i.e., from $10^{5} \mathrm{~Hz}$ to $10^{-2} \mathrm{~Hz}$. Apparently, these plots only displayed a single arc. Nevertheless, a second arc can be observed changing the scale of the high-frequency region as it shows on the right column of Figure 10. This effect was due to the fact that the low-frequency arcs presented impedance values several orders of magnitude higher than the high-frequency arcs. The high-frequency arc of this kind of plot is generally related to the electrical properties of the coating [56,57]. The low-frequency arc is associated with the corrosive process of the metal substrate on the base of the pores of the coating [56,57]. Nevertheless, some cautions must be taken into account. Walter and Feliu et al. described situations where the HFA can interact with the LFA, causing difficulties in separating the contributions of the coating and corrosive process in the drawing of the Nyquist plots [57,58].

Figure 11 shows Bode plots of the same impedance data described above. The left column in Figure 11 shows the variations of the impedance modulus $(|Z|)$ vs. frequency on a double-logarithmic scale. The right column of Figure 11 shows the phase angle vs. frequency in a semi-logarithmic. The Bode plots showed again the influence of two time constants but for long-term immersion tests, a new effect can be observed at the lowest frequencies. This effect is usually ascribed to diffusion phenomena associated with the progressive deterioration of the coating [57]. The gradual decrease of the impedance modulus values with immersion time suggests that the 21,31 and 41 sol-gel coatings slowly lost their barrier properties during the elapsing of the immersion tests $[57,58]$. 
Sample 21 (MAPTMS/TMOS molar ratio = 2:1)
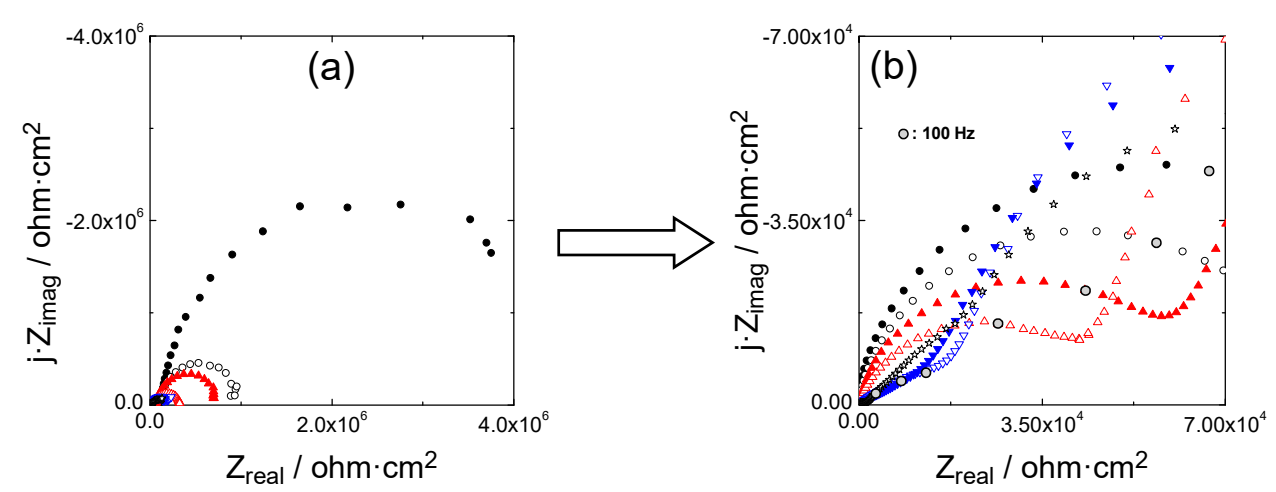

Sample 31 (MAPTMS/TMOS molar ratio = 3:1)
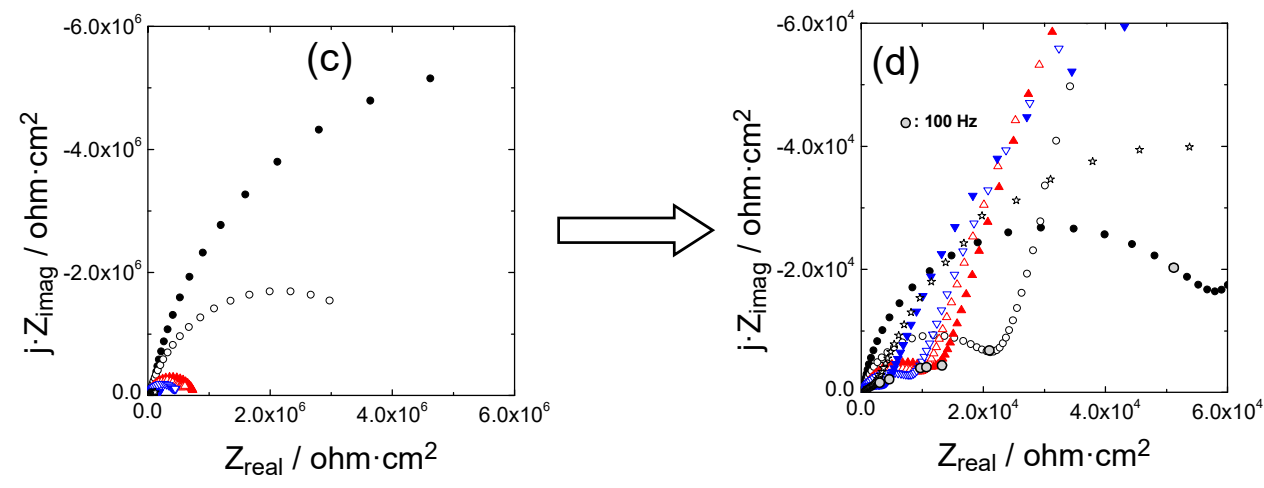

Sample $41($ MAPTMS/TMOS molar ratio $=4: 1)$
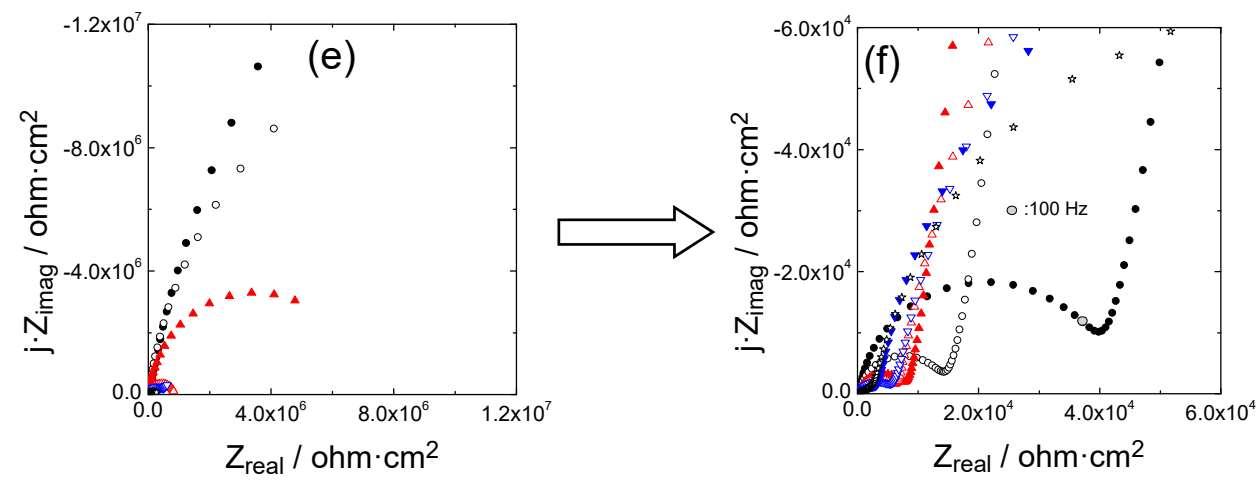

•: $1 \mathrm{~h}, \circ: 4 \mathrm{~h}, \Delta: 8 \mathrm{~h}, \triangle: 12 \mathrm{~h}, \mathbf{\nabla}: 24 \mathrm{~h}, \nabla: 48 \mathrm{~h}, \star: 72 \mathrm{~h}$

Figure 10. Nyquist impedance plots for different AA2024-T3/sol-gel coating systems: sample 21 (a,b), sample 31 (c,d) and sample $41(\mathbf{e}, \mathbf{f})$. Test electrolyte: $0.05 \mathrm{M} \mathrm{NaCl}$ aqueous solution. Immersion time: 1 h, $4 \mathrm{~h}, 8 \mathrm{~h}, 12 \mathrm{~h}, 24 \mathrm{~h}, 48 \mathrm{~h}$ and $72 \mathrm{~h}$. 
Sample 21 (MAPTMS/TMOS molar ratio = 2:1)
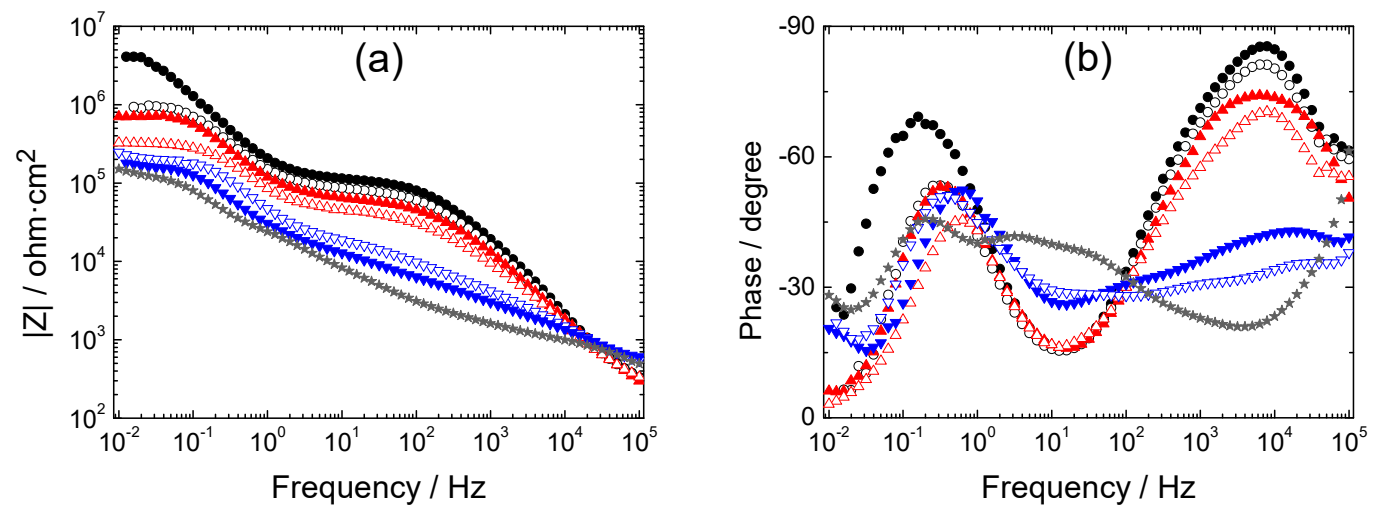

Sample 31 (MAPTMS/TMOS molar ratio = 3:1)
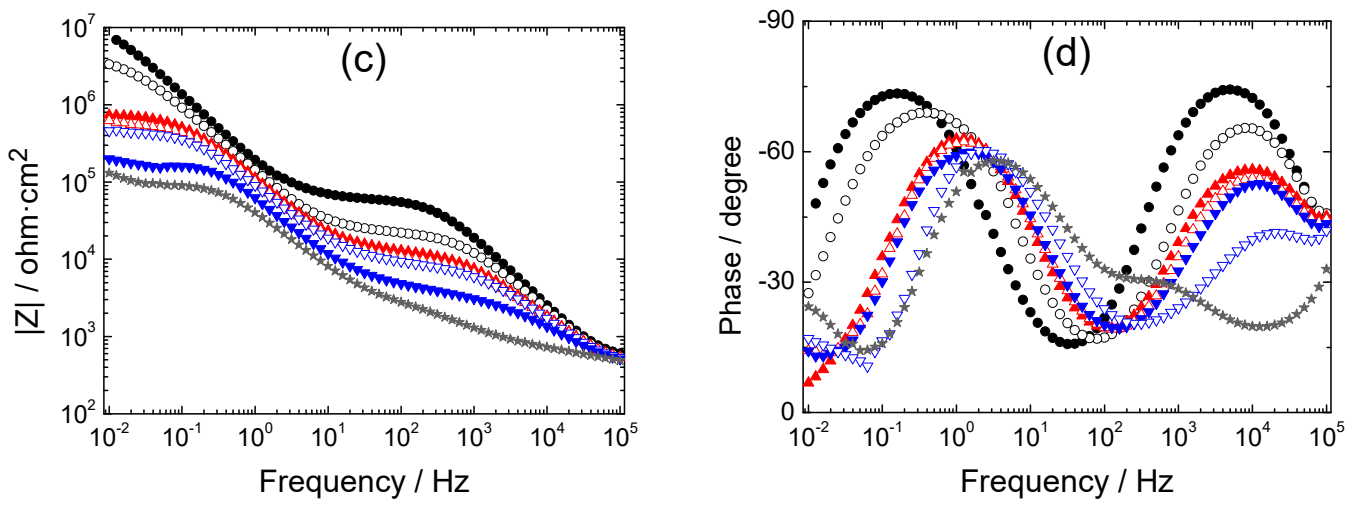

Sample 41 (MAPTMS/TMOS molar ratio = 4:1)
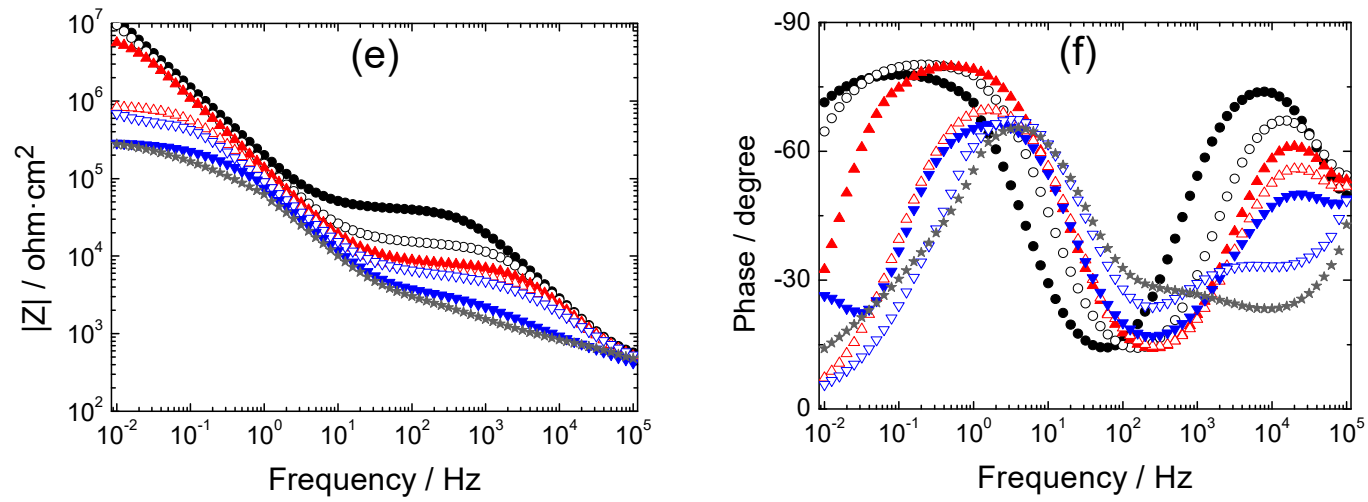

•: $1 \mathrm{~h}, 0: 4 \mathrm{~h}, \Delta: 8 \mathrm{~h}, \triangle: 12 \mathrm{~h}, \mathbf{\nabla}: 24 \mathrm{~h}, \nabla: 48 \mathrm{~h}, \star: 72 \mathrm{~h}$

Figure 11. Bode impedance plots for different AA2024-T3/sol-gel coating systems: sample $21(\mathbf{a}, \mathbf{b})$, sample $31(\mathbf{c}, \mathbf{d})$ and sample $41(\mathbf{e}, \mathbf{f})$. Test electrolyte: $0.05 \mathrm{M} \mathrm{NaCl}$ aqueous solution. Immersion time: $1 \mathrm{~h}, 4 \mathrm{~h}, 8 \mathrm{~h}, 12 \mathrm{~h}, 24 \mathrm{~h}, 48 \mathrm{~h}$ and $72 \mathrm{~h}$.

\subsection{EIS Measurements on Modified Sol-Gel Films}

Nyquist and Bode plots obtained for the 212 and 21PIP aluminum alloy coated samples showed a different evolution from that observed for the unmodified sol-gel/metal alloys systems (Figure 12). 
For Sample 212, Both high- and low-frequency arcs tended to bend toward the resistive axis during immersion tests as it was with unmodified systems (Figure 12a). However, it can be observed that the projection of these arcs cuts to the real axis at impedance values several orders of magnitude higher than the impedance arcs of the AA2024-T3 alloy samples coated with the unmodified sol-gel films.

Sample 212
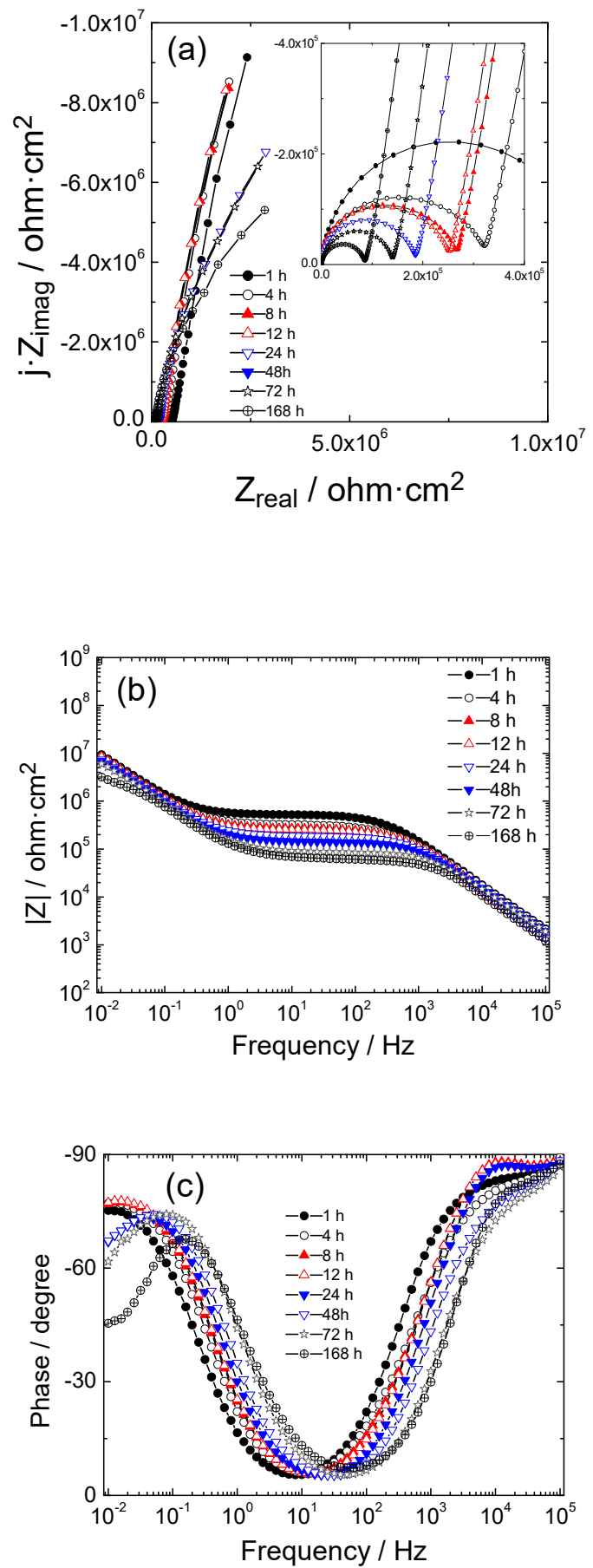

Sample 21PIP
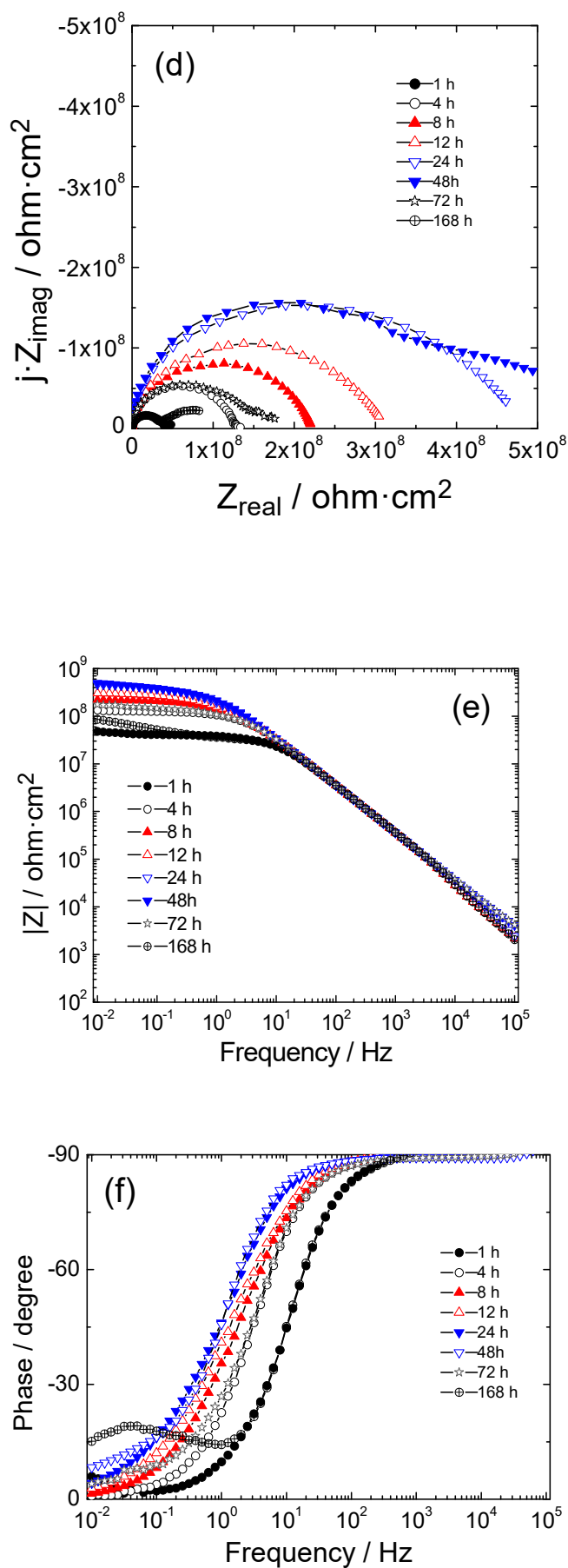

Figure 12. Nyquist and Bode impedance plots for different AA2024-T3/sol-gel coating systems: sample $212(\mathbf{a}-\mathbf{c})$ and sample 21PIP (d-f). Test electrolyte: $0.05 \mathrm{M} \mathrm{NaCl}$ aqueous solution. Immersion time: $1 \mathrm{~h}$, $4 \mathrm{~h}, 8 \mathrm{~h}, 12 \mathrm{~h}, 24 \mathrm{~h}, 48 \mathrm{~h}, 72 \mathrm{~h}$ and $168 \mathrm{~h}$. 
The modification of the films by adding small quantities of piperazine to the sol-gel formulations affected dramatically the corrosion protection behavior of the resulting films. The impedance plots of the 21PIP sample are represented in the right column of Figure $12 \mathrm{~d}-\mathrm{f}$. The most interesting feature of the piperazine-modified sol-gel sample is the notable increase of the impedance values obtained at the lowest frequencies for the early stages of the immersion tests. For the late stages, this trend inverted and the impedance values tended to decrease slowly, but they always were significantly higher than those measured for the undoped samples. This behavior can be ascribed to the passivation of the metal substrate due to the piperazine release across the film [59].

\subsection{Equivalent Circuit Models for Analyzing the Electrochemical Impedance Spectroscopy Data of the AA2024-T3 Alloy/Sol-Gel Film Systems}

The impedance plots have been analyzed by using equivalent circuits and complex nonlinear least-squares (CNLS) methods. Figure 13 shows three electrical equivalent circuits used for these analyses. These models are based on some modifications of the classical equivalent circuit proposed by Beaunier et al. [56]. $R_{S}$ is associated with the solution resistance of the bulk electrolyte. $R_{\text {coat }}$ represents the resistance of the coating pores impregnated with the electrolyte. $\mathrm{CPE}_{\mathrm{coat}}$ is a constant phase element associated with the non-porous areas of the coating. The $\mathrm{R}_{\mathrm{ct}}$ electrical element represents the charge transfer resistance associated with the corrosive process and $\mathrm{CPE}_{\mathrm{dl}}$ to a constant phase element associated with the electrochemical double layer at metal/electrolyte interface both at the base of pores and damaged areas that develop in the coating during immersion in the corrosive media [60]. Finally, $\mathrm{CPE}_{2}$ represents the oxide layer covering the AA2024-T3 alloys [61,62] and $\mathrm{W}_{\mathrm{S}}$ is the Warburg impedance which is associated with the finite-length diffusion process that takes place within pores of the sol-gel coating [58].

(a)

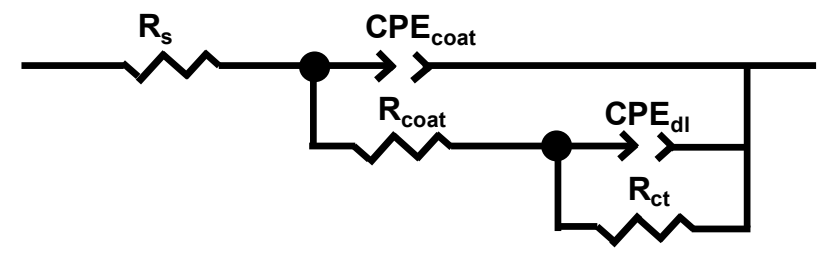

(b)
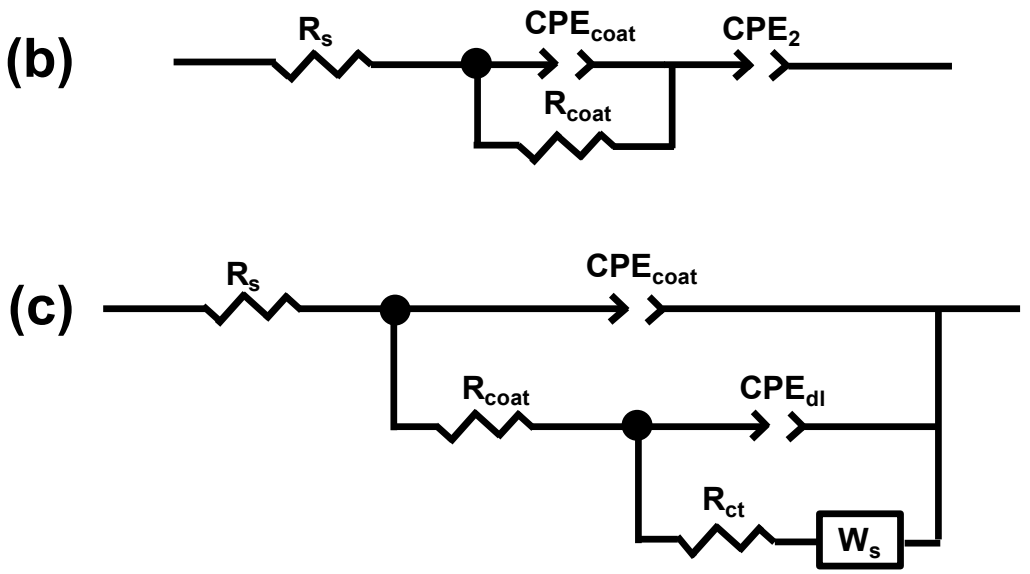

Figure 13. Equivalent circuits (a-c) used for fitting and modeling the experimental impedance data.

In this study, the capacitors of the equivalent circuit proposed by Beaunier have been replaced by the constant phase elements (CPEs) to take in account the non-ideal capacitive behavior of these metal/coating systems. The CPE impedance is defined by using the parameters $\alpha$ and $Q$ as:

$$
Z(\omega)=1 / Q(j \omega)^{\alpha}
$$


where $j$ is the imaginary number $(j=\sqrt{ }-1), Q$ is the CPE constant $\left(s^{\alpha} / \Omega \cdot \mathrm{cm}^{2}\right.$ or $\left.F \cdot s^{\alpha-1}\right) / \mathrm{cm}^{2}, \omega$ is the angular frequency $\left(\mathrm{rad} \cdot \mathrm{s}^{-1}\right)$ and $\alpha$ is a dimensionless number independent of frequency $[62,63]$. When $\alpha=1$, the CPE describes an ideal capacitor; for $\alpha=0$, the CPE is an ideal resistor; for $\alpha=0.5$, the CPE represents a Warburg diffusional impedance. In the case of a parallel connection of constant phase elements $\mathrm{CPE}$ and a resistance $\mathrm{R}$, the relationship between the capacitance $\mathrm{C}$ and the associated CPE can be calculated by using the following Equation [45,46]:

$$
C=\left(Q^{(1-\alpha)}\right)^{1 / \alpha}
$$

This Equation is similar to the formula proposed by Hsu and Mansfeld to relate $\mathrm{C}$ and $\mathrm{Q}$ in terms of the characteristic angular frequency $\omega_{\max }[64]$ :

$$
C=Q\left(\omega_{\max }\right)^{(\alpha-1)}
$$

The validity of results obtained by applying electrical equivalent circuits and CNLS procedures was estimated taking in account not just the quality of the fit plots generated, but also the lower chi-square $\left(\chi^{2}\right)$ values, lower weighted sum of squares (WSS) and the estimative errors (in \%) for all the electrical components of the chosen equivalent circuits. Figure 14 shows a representative example of the procedure followed to obtain and validate the fitting results. The example corresponds to the analysis of Sample 21 after $1 \mathrm{~h}$ of immersion time in $0.05 \mathrm{M} \mathrm{NaCl}$ aqueous solution. For this analysis, the equivalent circuit shown in Figure 13a was used. Figure 14a shows the parameters selected for the calculous and fitting process. Figure $14 \mathrm{~b}$ shows the fitting values obtained for each electrical element of the equivalent circuit, estimative errors in percent, weighted sum of squares and $\chi^{2}$ values. The experimental Nyquist and Bode plots and the corresponding fitting plots are compared in Figure 14c,d.

For short-term EIS testing, the best-fitted electrical equivalent circuit (EEC) for samples 21, 31, 41 and 21PIP was the electrical model shown in Figure 13a. This is the typically equivalent circuit used for describing the electrochemical behavior of metal/coating systems based on porous films [56-58]. An exception to this behavior has been observed for sample 212 whose impedance plots for short-term EIS testing can be better described by the EEC shown in Figure 13b. A similar equivalent circuit was successfully used by Musiani et al. for the determination of resistivity profiles in anti-corrosion coatings and, to describe the constant phase element behavior caused by coupled resistivity and permittivity distributions in films [65].

Figure 15 shows the evolution of the resistance and capacitance values $\left(\mathrm{R}_{\text {coat }}, \mathrm{R}_{\mathrm{tc}}, \mathrm{C}_{\text {coat }}\right.$ and $\left.\mathrm{C}_{\mathrm{dl}}\right)$ for all the sol-gel film/AA2024-T3 alloy systems during the immersion tests in the $0.05 \mathrm{M} \mathrm{NaCl}$ aqueous solution. Figure 15a shows that between 0 and $48 \mathrm{~h}$ of immersion, the $R_{\text {coat }}$ values of sample 21 are sensibly higher than for samples 31 and 41 . Higher $R_{\text {coat }}$ values are associated with better barrier properties against corrosion. This was one of the reasons that during the iterative of optimization of the sol-gel formulations we chose the samples of MAPTMS/TMOS of molar ratio $=2: 1$.

It also is remarkable to observe that the $R_{\text {coat }}$ and $R_{c t}$ values obtained for 212 and 21PIP samples were several orders of magnitude higher than those values measured samples for 21, 31 and 41 for both short and long immersion tests (Figure 15a,b).

It is interesting to note in Figure 15a,b that for the short-term tests, the values obtained for $R_{\text {coat }}$ and $R_{\mathrm{ct}}$ increased over time for the 21PIP sample.

This behavior can be related to the turn-on of an active protection mechanism and the inhibition of corrosion due to the release of piperazine physically trapped or nanoencapsulated in the network of the films of modified sol-gel toward the pore base and defects generated in the coatings during working conditions. 


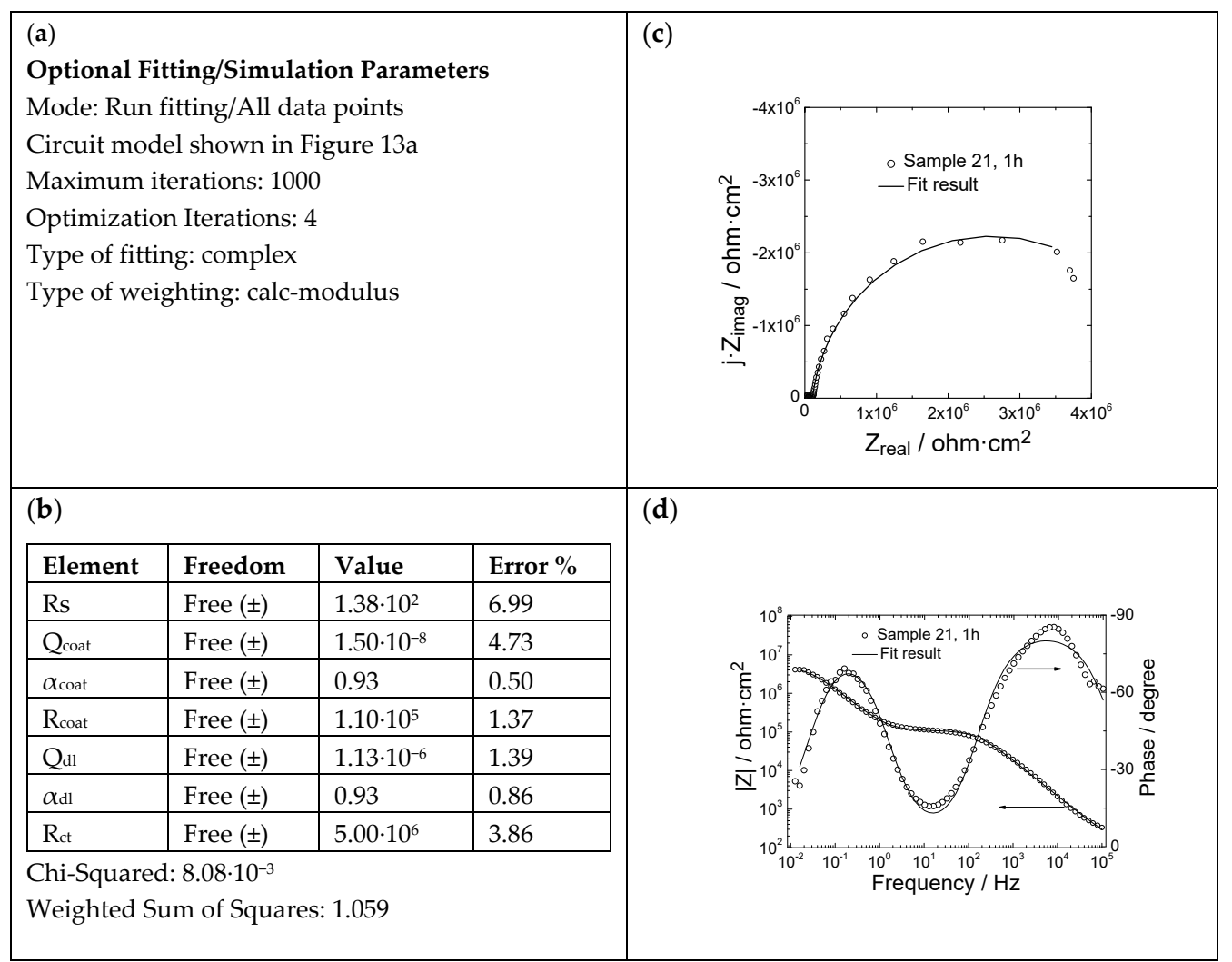

Figure 14. Fitting parameters and results obtained by applying calculous protocols of the ZView ${ }^{\circledR}$ commercial software, for sample 21 after $1 \mathrm{~h}$ of immersion time in $0.05 \mathrm{M} \mathrm{NaCl}$ aqueous solution: (a) optional fitting parameters; (b) values obtained for each element of the equivalent circuit shown in Figure 13a; (c,d) Nyquist and Bode plots of experimental and fitting data respectively.

Figure $15 c$,d shows large differences in $C_{\text {coat }}$ and $C_{d l}$ values for samples 21, 31 and 41 compared to those obtained for samples 212 and 21PIP. These capacitance values were calculated from the corresponding $\alpha$ and $Q$ parameters of the CPEs by using Equation (2) The $C_{\text {coat }}$ values depend upon both the chemical and physical nature of the organic-inorganic sol-gel film, particularly of the thickness, chemical composition and microscopic structure of the film [58]. For this reason, the change of $C_{\text {coat }}$ values obtained overtime can be ascribed not just to the water abortion but also to certain geometric changes produced in the film during the immersion tests [58]. Figure $15 \mathrm{c}$ shows that the $\mathrm{C}_{\text {coat }}$ values of 21, 31 and 41 sol-gel films were several orders of magnitude higher than those obtained for 212 and 21PIP samples throughout the test time. The $\mathrm{C}_{\text {coat }}$ values obtained for the unmodified sol-gel films were reasonable for short-term tests, but Figure $15 \mathrm{c}$ shows they gradually increased quite fast during the immersion tests. Van Westing et al. reported that sometimes for long-term tests the $\mathrm{C}_{\text {coat }}$ plots versus immersion time showed a gradual increase and did not reach a plateau or steady-state value despite that these films reached full saturation of water. They interpreted this increase observed for $\mathrm{C}_{\text {coat }}$ values could be due to the swelling of the film [66]. In contrast, the $\mathrm{C}_{\text {coat }}$ values measured for samples 212 and 21PIP were several orders of magnitude lower and they remained more or less constant over time (Figure 15b). This behavior could be associated with the inalterability of these films. 
(a)

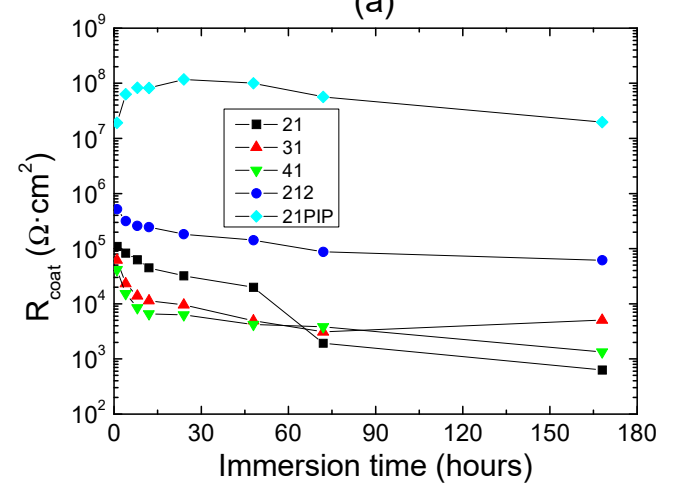

(c)

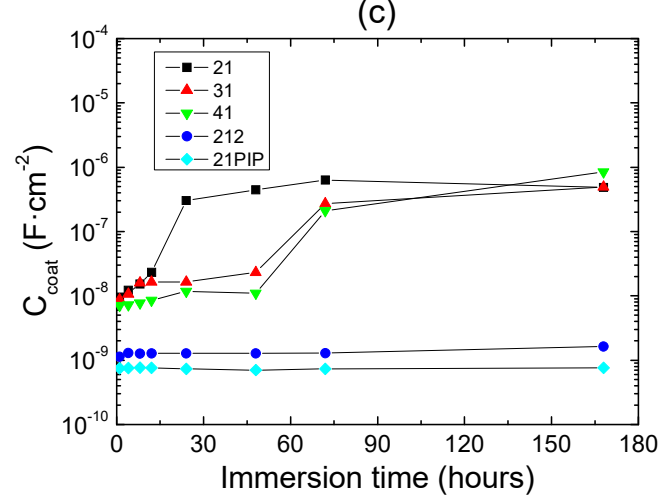

(b)

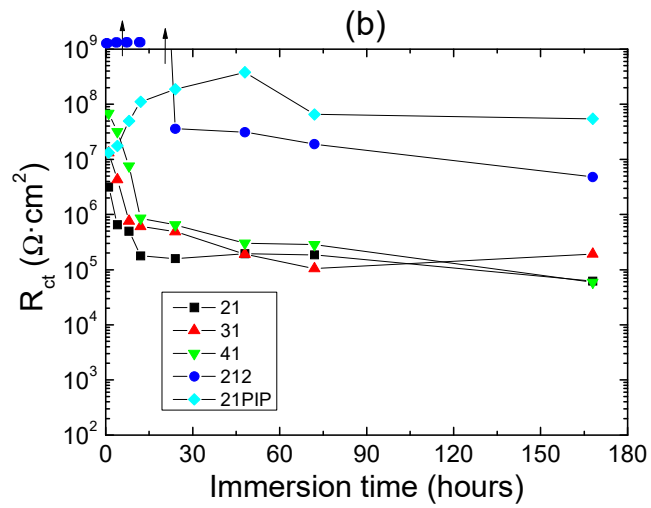

(d)

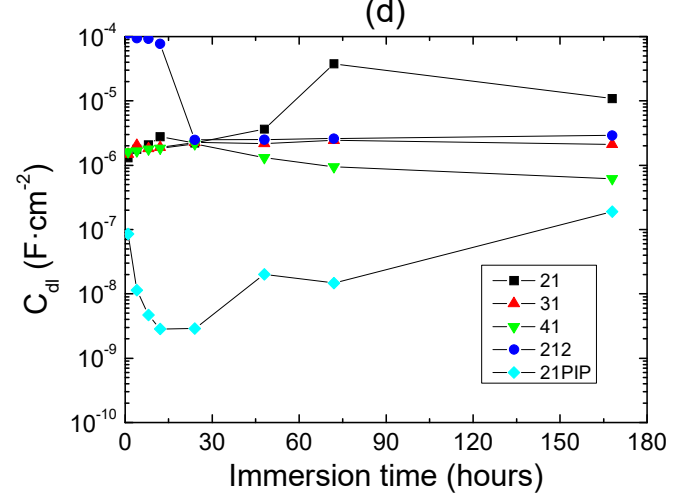

Figure 15. Evolution of the electrical element values of the proposed equivalent circuit during immersion tests: (a) $\mathrm{R}_{\text {coat }}$, (b) $\mathrm{C}_{\text {coat }}$ (c) $\mathrm{R}_{\mathrm{ct}}$ and (d) Cdl. Samples: 21, 31, 41, 212 and 21PIP. Test electrolyte: $0.05 \mathrm{M}$ $\mathrm{NaCl}$ solution.

Figure $15 \mathrm{~d}$ shows the evolution of $\mathrm{C}_{\mathrm{dl}}$ values during immersion tests in $0.05 \mathrm{M} \mathrm{NaCl}$ aqueous solution. The $\mathrm{C}_{\text {coat }}$ values depended almost exclusively upon changes occurring at the microscopic level. In contrast, the double-layer capacitance $\left(\mathrm{C}_{\mathrm{dl}}\right)$ was affected by macroscopic failures and by the total metallic surface area available to the corrosive process at the base of the pores and perforations developed on the films during the immersion tests. For good barrier films, at the beginning of the immersion test, $C_{\mathrm{dl}}$ will be extremely small in values as it is the case of the 21PIP metal/film system. In contrast, the $C_{d l}$ values of the samples unmodified with piperazine were several orders of magnitude lesser than those found for the 21PIP sample.

By comparing the values of the electrical components of the equivalent circuits, it is possible to rank the long-term corrosion protection performance of the different sol-gel films. In Figure 15a, it can be observed that, for example, for a fixed test time of $72 \mathrm{~h}$, the $R_{\text {coat }}$ of samples show the following sequence:

$$
\text { 21PIP >> } 212>>41>31>21
$$

On the other hand, Figure $15 \mathrm{c}$ shows that for $\mathrm{C}_{\text {coat }}$ values, such a sequence changes to:

$$
21 \text { PIP }<212<<41<31<21
$$

From these results, it can be deduced that the 21PIP metal/sol-gel film system shows the best barrier properties and corrosion resistance behavior. 
It could be remarkable to indicate that these results are in agreement with those obtained by applying ${ }^{29} \mathrm{Si}-\mathrm{NMR}$. Thus the best barrier properties recognized by EIS correspond with the higher crosslinked degree identified by ${ }^{29} \mathrm{Si}-\mathrm{NMR}$.

\subsection{Local Electrochemical Impedance Mapping (LEIM)}

Local electrochemical impedance mapping (LEIM) can give valuable information on the mechanism of corrosion on a controlled defect made on coated metal samples $[49,67,68]$. Previous studies have shown that for the correct detection of heterogeneities in solid/liquid interfaces by using local electrochemical impedance, it is necessary to select adequate input AC signal frequency and ranges of electrolyte conductivity $[69,70]$. Taking into account those criteria, two different AC signal frequencies were chosen for collecting local electrochemical impedance maps (LEIM): 5000 and $10 \mathrm{~Hz}$, respectively. It was expected that the impedance maps collected at high frequency $(5000 \mathrm{~Hz})$ provided information on the evolution of the degradation processes of the sol-gel coating during the immersion tests. On the other hand, the impedance maps recorded at a lower frequency $(10 \mathrm{~Hz})$ provide information on the evolution of the corrosion behavior into the artificial defect made previously on the sol-gel film. Moreover, a low conductivity electrolyte $(0.001 \mathrm{M} \mathrm{NaCl}$ aqueous solution) was selected to ensure an optimized lateral resolution of the LEIM measurements.

Figure 16 shows the local electrochemical impedance maps obtained after 4, 8, 12 and $24 \mathrm{~h}$ of immersion in $0.001 \mathrm{M} \mathrm{NaCl}$ aqueous solution at $5000 \mathrm{~Hz}$ for a 212 sample (top part of Figure 16a) and for a 21PIP sample (bottom part of Figure 16b). At this input frequency, no differences were observed between the maps obtained initially ( $4 \mathrm{~h}$ immersion) and those recorded at longer soaking times ( $24 \mathrm{~h}$, Figure 16a). These maps show that the sol-gel film remains stable over all test times. On the other hand, for the 21PIP sample, the impedance values of the map recorded at $4 \mathrm{~h}$ of immersion were higher than for those maps obtained for the 212 sample (Figure 16a,b). It can also be observed that these impedance values presented a slowly decreasing rate when the immersion test elapsed from 4 to $12 \mathrm{~h}$. From 12 to 24 immersion hours, the impedance values of the 21PIP sample remained more or less constant (Figure 16b). However, these results indicated that both sol-gel films exhibited good stability during the immersion tests. It is also remarkable that the sol-gel film modified with piperazine (21PIP samples) showed higher impedance values, i.e., higher barrier properties than the undoped films (212 samples).

Figures 17 and 18 show the local electrochemical impedance maps obtained at an input frequency of $10 \mathrm{~Hz}$ for different exposure time $(2,4,6$ and $12 \mathrm{~h})$ in the $0.001 \mathrm{M} \mathrm{NaCl}$ aqueous solution for the 212 and 21PIP samples respectively. On the artificial defect of sample 212, the impedance values decreased when the exposure time to the aggressive media increased (Figure 17). These results indicated that no inhibitive action appears in the undoped sol-gel films. In contrast, Figure 18 shows a different trend for the 21PIP sample. From 2 to $4 \mathrm{~h}$ of immersion, these samples remained stable, without observing significant changes in the registered impedance values. After $12 \mathrm{~h}$ of immersion, the local electrochemical impedance maps around the artificial defect showed an increase of the impedance values which can be associated with a decrease of the corrosion activity on the naked areas of the metal substrate. These results confirmed that the piperazine-modified sol-gel films worked through an active corrosion protection mechanism. Thus, due to the release of piperazine from the sol-gel film to the artificial defect produced the passivation of the metallic substrate and the sealing of the defect. 
a)

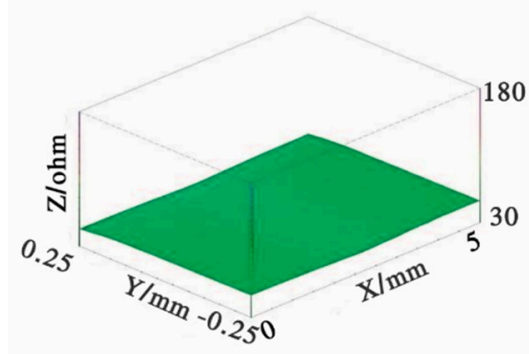

$12 \mathrm{~h}$

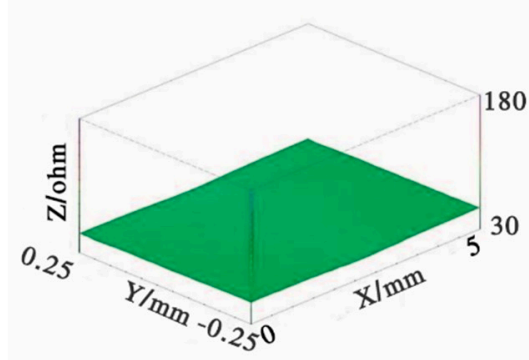

b)

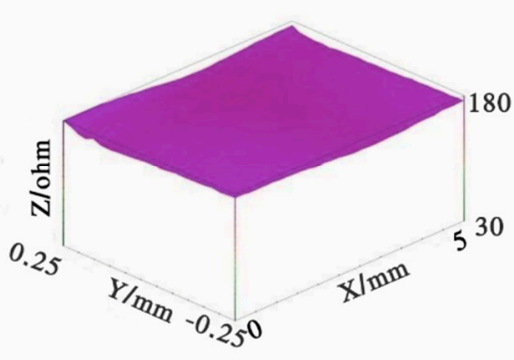

$12 \mathrm{~h}$

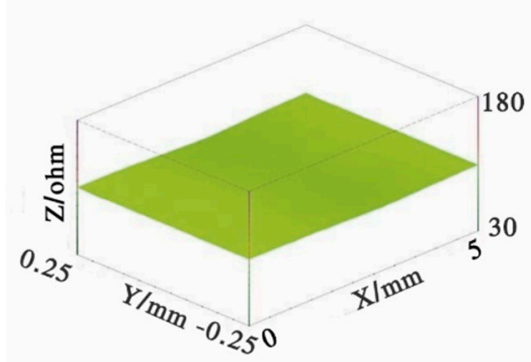

$8 h$

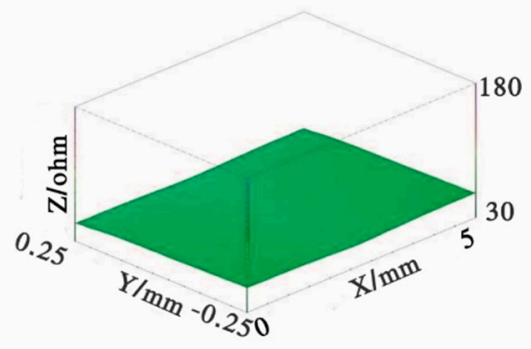

$24 h$

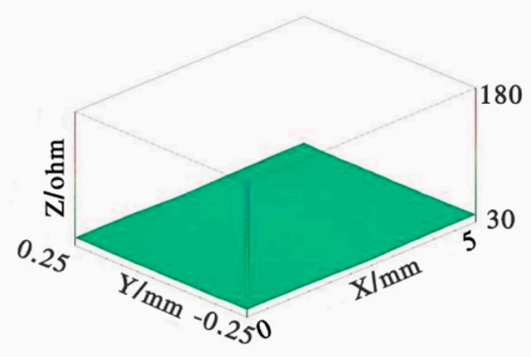

$8 h$

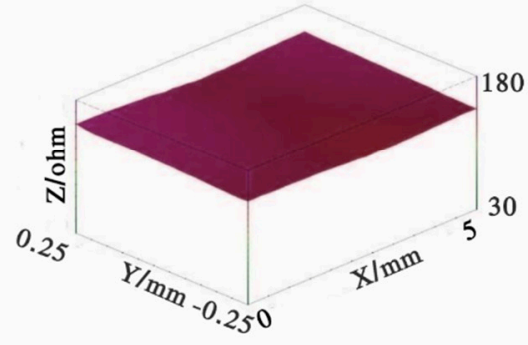

$24 \mathrm{~h}$

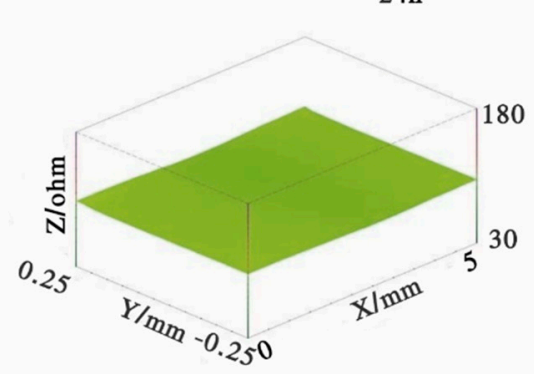

Figure 16. Local electrochemical impedance maps (LEIM) obtained for samples 212 (a) and 21PIP (b). Frequency: $5000 \mathrm{~Hz}$. Immersion time: 4, 8, 12 and $24 \mathrm{~h}$. Electrolyte: $0.001 \mathrm{M} \mathrm{NaCl}$ aqueous solution. 

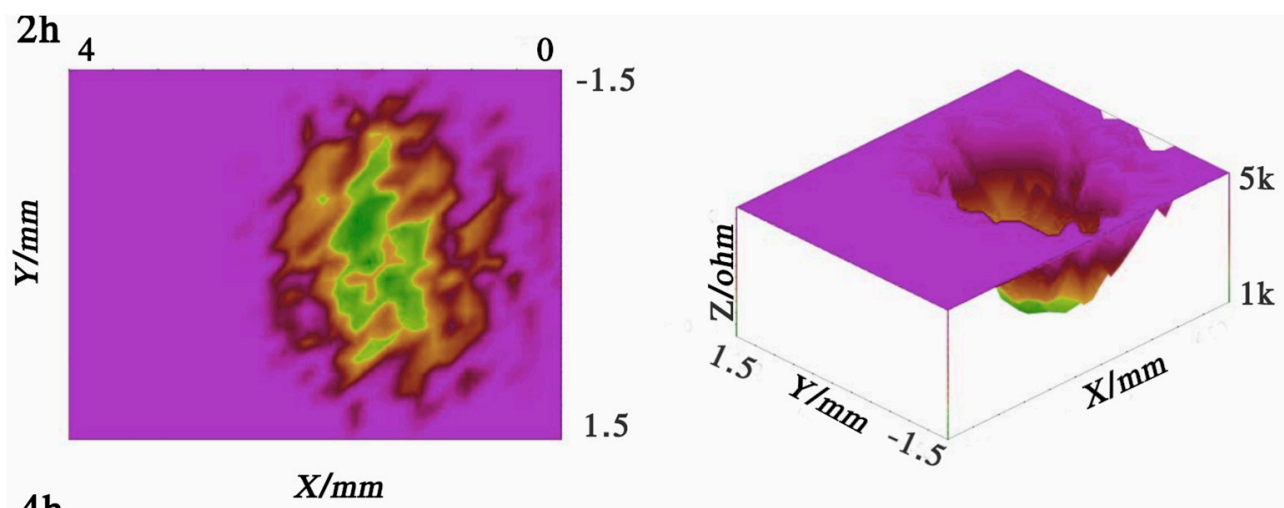

4h
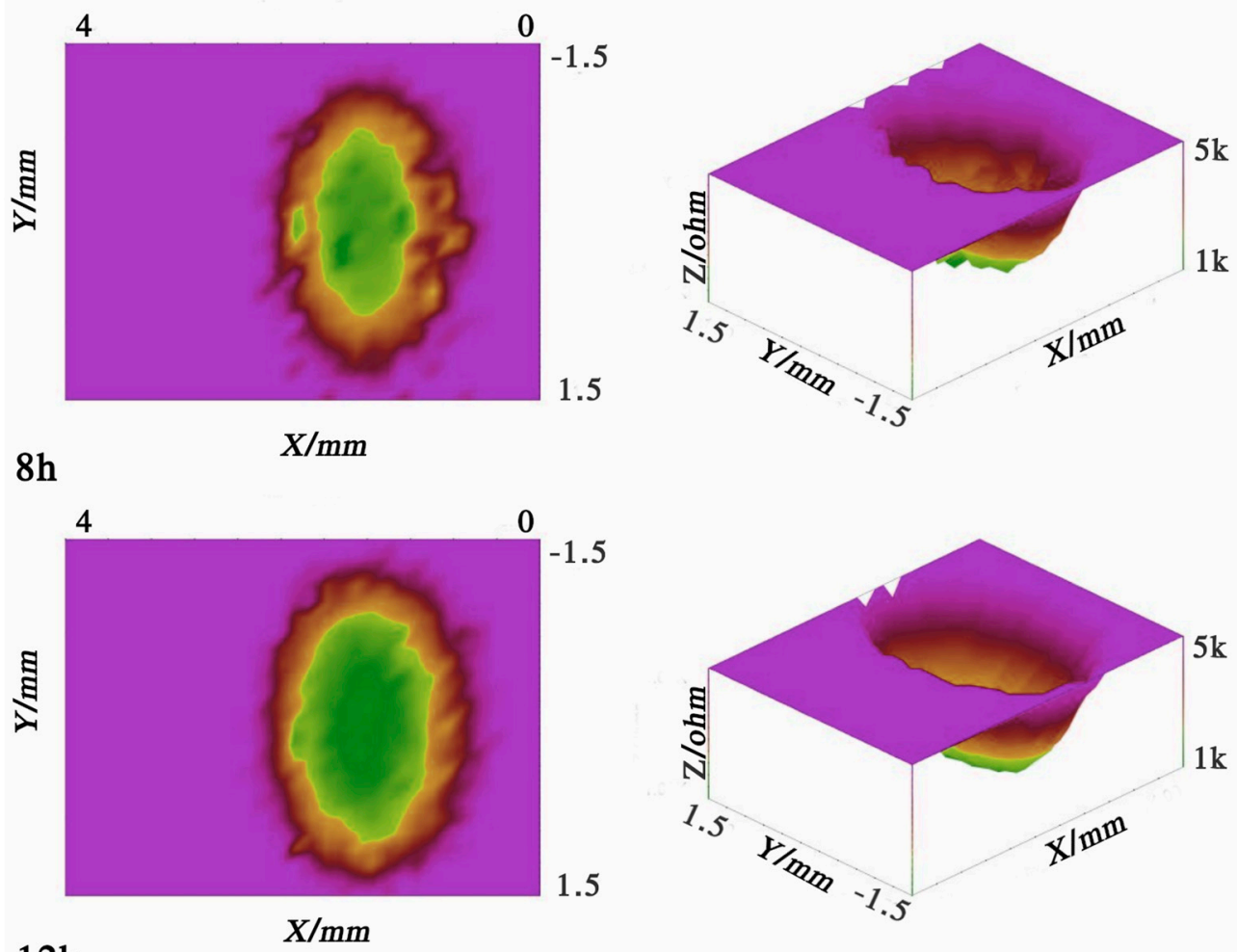

$12 \mathrm{~h}$
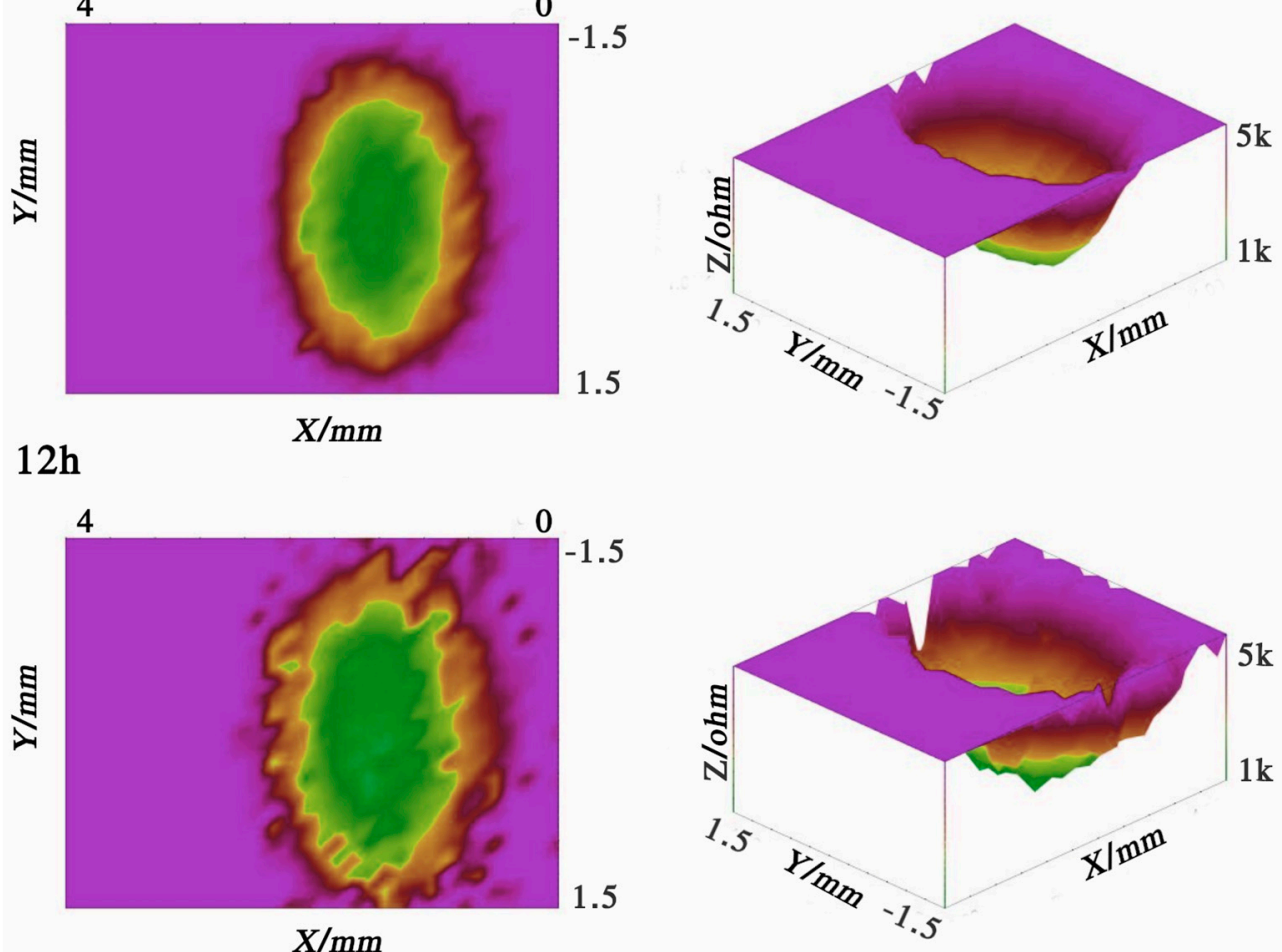

Figure 17. Local electrochemical impedance maps (LEIM) obtained for the 212 sample. Frequency: 10 Hz. Immersion time: 2, 4, 8 and $12 \mathrm{~h}$. Electrolyte: $0.001 \mathrm{M} \mathrm{NaCl}$ aqueous solution. 

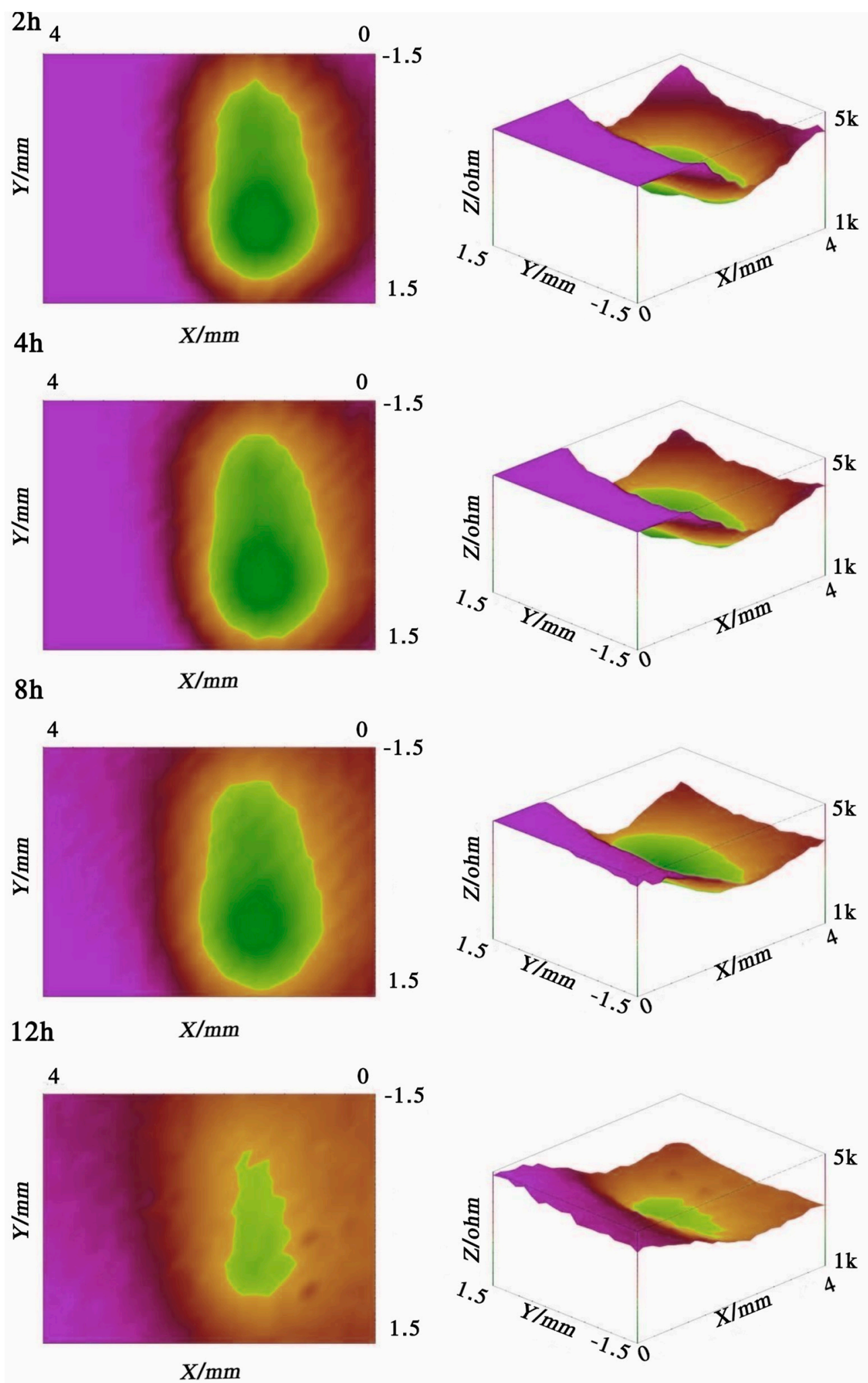

Figure 18. Local electrochemical impedance maps (LEIM) obtained for the 21PIP sample. Frequency: $10 \mathrm{~Hz}$. Immersion time: 2, 4, 8 and $12 \mathrm{~h}$. Electrolyte: $0.001 \mathrm{M} \mathrm{NaCl}$ aqueous solution.

\section{Conclusions}

Piperazine-modified methacrylate- $\mathrm{SiO}_{2}$ hybrid films have been successfully prepared by the sol-gel method. 
The first step of the research was devoted to preparing different sol-gel formulations by adjusting the MAPTMS/TMOS molar ratio and optimizing the physical-chemical characteristics and enhancing the electrochemical corrosion properties of methacrylate- $\mathrm{SiO}_{2}$ hybrid films deposited on AA2024-T3 aluminum alloy.

In the second step, these sol-gel films were modified by adding piperazine to the sol formulations. Piperazine incorporation in the organopolysiloxane network dramatically increased the sol viscosity and thickness of the films as well as the crosslinking degree and polymerization, as confirmed by FTIR and ${ }^{29}$ Si-NMR spectroscopies

EIS and LEIM have shown that the addition of piperazine significantly improves the anticorrosive behavior of MAPTMS/TMOS films. This performance can be attributed not only to the increase of the crosslinking degree and thickness of the piperazine-modified sol-gel films, but also to the improvement of the active protection properties provided by this corrosion inhibitor.

These sol-gel pretreatments can be an eco-friendly alternative to the traditional chromate conversion coatings (CCCs) for the protection of surfaces of aluminum alloy 2024-T3.

Author Contributions: Conceptualization, V.J.G., A.J.-M. and J.C.G.; methodology, D.J.C., R.M., V.J.G., A.J.-M. and J.C.G.; software, D.J.C. and R.M.; validation, D.J.C., V.J.G. and R.M.; formal analysis, D.J.C. and R.M.; investigation, D.J.C., R.M., V.J.G., A.J.-M. and J.C.G.; resources, V.J.G., D.J.C. and R.M.; data curation, D.J.C. and R.M.; writing-original draft preparation, D.J.C., R.M., A.J.-M. and J.C.G.; writing-review and editing, J.C.G.; visualization, R.M., A.J.-M. and J.C.G.; supervision, A.J.-M. and J.C.G.; project administration, A.J.-M. and J.C.G.; funding acquisition, A.J.-M. and J.C.G. All authors have read and agreed to the published version of the manuscript.

Funding: This research was funded by the Ministry of Economy and Competitiveness of Spain (MAT2015-65445-C2-1-R and MAT2015-70780-C4-2-P Projects), and the Regional Government of Madrid (Project P2018/NMT-4411 ADITIMAT-CM).

Conflicts of Interest: The authors declare no conflict of interest.

\section{References}

1. Dursun, T.; Soutis, C. Recent developments in advanced aircraft aluminum alloys. Mater. Des. 2014, 56, 862-871. [CrossRef]

2. Zhang, X.; Jiao, Y.; Yu, Y.; Liu, B.; Hashimoto, T.; Liu, H.; Dong, Z. Intergranular corrosion in AA2024-T3 aluminum alloy: The influence of stored energy and prediction. Corros. Sci. 2019, 155, 1-12. [CrossRef]

3. Trdan, U.; Sano, T.; Klobčar, D.; Sano, Y.; Grum, J.; Šturm, R. Improvement of corrosion resistance of AA2024-T3 using femtosecond laser peening without protective and confining medium. Corros. Sci. 2018, 143, 46-55. [CrossRef]

4. Boag, A.; Hughes, A.E.; Glenn, A.M.; Muster, T.H.; McCulloch, D. Corrosion of AA2024-T3 Part I: Localised corrosion of isolated IM particles. Corros. Sci. 2011, 53, 17-26. [CrossRef]

5. Hughes, A.E.; Boag, A.; Glenn, A.M.; McCulloch, D.; Muster, T.H.; Ryan, C.; Luo, C.; Zhou, X.; Thompson, G.E. Corrosion of AA2024-T3 Part II: Co-operative corrosion. Corros. Sci. 2011, 53, 27-39. [CrossRef]

6. Mitton, D.B.; Carangelo, A.; Acquesta, A.; Monetta, T.; Curioni, M.; Bellucci, F. Selected Cr(VI) replacement options for aluminum alloys: A literature survey. Corros. Rev. 2017, 35, 365-381. [CrossRef]

7. Becker, M. Chromate-free chemical conversion coatings for aluminum alloys. Corros. Rev. 2019, 37, 321-342. [CrossRef]

8. Kakde, V.; Mannari, V. Advanced chrome-free organic-inorganic hybrid pretreatments for aerospace aluminum alloy 2024-T3-application of novel bis-ureasil sol-gel precursors. J. Coat. Technol. Res. 2009, 6, 201-211. [CrossRef]

9. Basu, B.J.; Srinivasan, A.; Manasa, J.; Grips, V.K.W. Improved corrosion protection of aluminum alloy AA 2024 by sol-gel hybrid coatings after surface pretreatment by silanization. Surf. Eng. 2012, 28, $294-299$. [CrossRef]

10. Yasakau, K.A.; Kuznetsova, A.; Kallip, S.; Starykevich, M.; Tedim, J.; Ferreira, M.G.S.; Zheludkevich, M.L. A novel bilayer system comprising LDH conversion layer and sol-gel coating for active corrosion protection of AA2024. Corros. Sci. 2018, 143, 299-313. [CrossRef] 
11. Gao, Z.; Zhang, D.; Hou, L.; Li, X.; Wei, Y. Understanding of the corrosion protection by V(IV) conversion coatings from a sol-gel perspective. Corros. Sci. 2019, 161, 108196. [CrossRef]

12. Lev, O.; Wu, Z.; Bharathi, S.; Glezer, V.; Modestov, A.; Gun, J.; Rabinovich, L.; Sampath, S. Sol-gel materials in electrochemistry. Chem. Mat. 1997, 9, 2354-2375. [CrossRef]

13. Zheludkevich, M.L.; Serra, R.; Montemor, M.F.; Miranda Salvado, I.M.; Ferreira, M.G.S. Corrosion protective properties of nanostructured sol-gel hybrid coatings to AA2024-T3. Surf. Coat. Technol. 2006, 200, 3084-3094. [CrossRef]

14. Zheludkevich, M.L.; Serra, R.; Montemor, M.F.; Yasakau, K.A.; Salvado, I.M.M.; Ferreira, M.G.S. Nanostructured sol-gel coatings doped with cerium nitrate as pre-treatments for AA2024-T3: Corrosion protection performance. Electrochim. Acta 2005, 51, 208-217. [CrossRef]

15. Schem, M.; Schmidt, T.; Gerwann, J.; Wittmar, M.; Veith, M.; Thompson, G.E.; Molchan, I.S.; Hashimoto, T.; Skeldon, P.; Phani, A.R.; et al. CeO2-filled sol-gel coatings for corrosion protection of AA2024-T3 aluminum alloy. Corr. Sci. 2009, 51, 2304-2315. [CrossRef]

16. Álvarez, D.; Collazo, A.; Hernández, M.; Nóvoa, X.R.; Pérez, C. Characterization of hybrid sol-gel coatings doped with hydrotalcite-like compounds to improve corrosion resistance of AA2024-T3 alloys. Prog. Org. Coat. 2010, 68, 91-299. [CrossRef]

17. Terada, M.; Queiroz, F.M.; Aguiar, D.B.S.; Ayusso, V.H.; Costenaro, H.; Olivier, M.-G.; De Melo, H.G.; Costa, I. Corrosion resistance of tartaric-sulfuric acid anodized AA2024-T3 sealed with Ce and protected with hybrid sol-gel coating. Surf. Coat. Technol. 2019, 372, 422-426. [CrossRef]

18. Hu, T.-H.; Shi, H.-W.; Wei, T.; Fan, S.-H.; Liu, F.-C.; Han, E.-H. Corrosion protection of AA2024-T3 by cerium malate and cerium malate-doped sol-gel coatings. Acta Metall. Sin. Engl. Lett. 2019, 32, 913-924. [CrossRef]

19. Figueroa, R.; Nóvoa, X.R.; Pérez, C. Hydrophobic surface treatments for improving the corrosion resistance of anodized AA2024-T3 alloys. Electroch. Acta 2019, 303, 56-66. [CrossRef]

20. Hegde, M.; Kavanagh, Y.; Duffy, B.; Tobin, E.F. Preliminary Evaluation of functional coatings for marine based renewable energy applications. Lect. Notes Mech. Eng. 2020, 672-683. [CrossRef]

21. Wang, D.; Bierwagen, G.P. Sol-gel coatings on metals for corrosion protection. Prog. Org. Coat. 2009, 64, 327-338. [CrossRef]

22. Figueira, R.B.; Fontinha, I.R.; Silva, C.J.R.; Pereira, E.V. Hybrid sol-gel coatings: Smart and green materials for corrosion mitigation. Coatings 2016, 6, 12. [CrossRef]

23. Ruiz-Hitzky, E.; Casal, B.; Aranda, P.; Galván, J.C. Inorganic-organic nanocomposite materials based on macrocyclic compounds. Rev. Inorg. Chem. 2001, 21, 125-159. [CrossRef]

24. Jiménez-Morales, A.; Galván, J.C.; Aranda, P. A new silver-ion selective sensor based on a polythiacrown-ether entrapped by sol-gel. Electrochim. Acta 2002, 47, 2281-2287. [CrossRef]

25. Garcia-Heras, M.; Jimenez-Morales, A.; Casal, B.; Galvan, J.C.; Radzki, S.; Villegas, M.A. Preparation and electrochemical study of cerium-silica sol-gel thin films. J. Alloy. Compd. 2004, 380, 219-224. [CrossRef]

26. Rosero-Navarro, N.C.; Pellice, S.A.; Durán, A.; Aparicio, M. Effects of Ce-containing sol-gel coatings reinforced with $\mathrm{SiO} 2$ nanoparticles on the protection of AA2024. Corr. Sci. 2008, 50, 1283-1291. [CrossRef]

27. Rosero-Navarro, N.C.; Paussa, L.; Andreatta, F.; Castro, Y.; Durán, A.; Aparicio, M.; Fedrizzi, L. Optimization of hybrid sol-gel coatings by combination of layers with complementary properties for corrosion protection of AA2024. Prog. Org. Coat. 2010, 69, 167-174. [CrossRef]

28. Paussa, L.; Rosero-Navarro, N.C.; Andreatta, F.; Castro, Y.; Duran, A.; Aparicio, M.; Fedrizzi, L. Inhibition effect of cerium in hybrid sol-gel films on aluminum alloy AA2024. Surf. Interface Anal. 2010, 42, 299-305. [CrossRef]

29. Andreatta, F.; Paussa, L.; Lanzutti, A.; Rosero Navarro, N.C.; Aparicio, M.; Castro, Y.; Duran, A.; Ondratschek, D.; Fedrizzi, L. Development and industrial scale-up of $\mathrm{ZrO} 2$ coatings and hybrid organic-inorganic coatings used as pre-treatments before painting aluminum alloys. Prog. Org. Coat. 2011, 72, 3-14, Cited 33 times. [CrossRef]

30. Rodič, P.; Milošev, I.; Lekka, M.; Andreatta, F.; Fedrizzi, L. Corrosion behavior and chemical stability of transparent hybrid sol-gel coatings deposited on aluminum in acidic and alkaline solutions. Prog. Org. Coat. 2018, 124, 286-295. [CrossRef]

31. Chattopadhyay, D.K.; Webster, D.C. Hybrid coatings from novel silane-modified glycidyl carbamate resins and amine crosslinkers. Prog. Org. Coat. 2009, 66, 73-85. [CrossRef] 
32. Croes, K.J.; Vreugdenhil, A.J.; Yan, M.; Singleton, T.A.; Boraas, S.; Gelling, V.J. An electrochemical study of corrosion protection by in situ oxidative polymerization in phenylenediamine crosslinked sol-gel hybrid coatings. Electrochim. Acta 2011, 56, 7796-7804. [CrossRef]

33. Woods, M.E.; Vreugdenhil, A.J. Continuously responsive epoxy-amine cross-linked silicon sol-gel materials. J. Coat. Technol. Res. 2006, 41, 7545-7554. [CrossRef]

34. Vreugdenhil, A.J.; Gelling, V.J.; Woods, M.E.; Schmelz, J.R.; Enderson, B.P. The role of crosslinkers in epoxy-amine crosslinked silicon sol-gel barrier protection coatings. Thin Solid Films 2008, 517, 538-543. [CrossRef]

35. Rathi, A.K.; Syed, R.; Shin, H.-S.; Patel, R.V. Piperazine derivatives for therapeutic use: A patent review (2010-present). Expert Opin. Ther. Patents 2016, 26, 777-797. [CrossRef]

36. Gao, H.; Zhang, X.; Pu, X.-J.; Zheng, X.; Liu, B.; Rao, G.-X.; Wan, C.-P.; Mao, Z.-W. 2-Benzoylbenzofuran derivatives possessing piperazine linker as anticancer agents. Bioorg. Med. Chem. Lett. 2019, 29, 806-810. [CrossRef]

37. Mazzotta, S.; Marrugal-Lorenzo, J.A.; Vega-Holm, M.; Serna-Gallego, A.; Álvarez-Vidal, J.; Berastegui-Cabrera, J.; Pérez del Palacio, J.; Díaz, C.; Aiello, F.; Pachón, J.; et al. Optimization of piperazine-derived ureas privileged structures for effective antiadenovirus agents. Eur. J. Med. Chem. 2020, 185, 111840. [CrossRef]

38. Ashraf, M.A.; Liu, Z.; Li, C.; Peng, W.-X.; Hemmati, A.; Hemmati, A. Assessment of mass transfer correlations used in post-combustion $\mathrm{CO}_{2}$ capture by piperazine activated 2-amino-2-methyl-1-propanol (a-AMP). J. Nat. Gas Sci. Eng. 2020, 73, 103051. [CrossRef]

39. Yuan, Y.; Rochelle, G.T. $\mathrm{CO}_{2}$ absorption rate and capacity of semi-aqueous piperazine for $\mathrm{CO}_{2}$ capture. Int. J. Greenh. Gas. Control. 2019, 85, 182-186. [CrossRef]

40. Safdar, R.; Omar, A.A.; Lal, B. Performance of aqueous tetrabutylammonium hydroxide, piperazine and their blends for carbon dioxide capture. J. Mol. Liq. 2018, 266, 522-528. [CrossRef]

41. Lin, F.-W.; Xu, X.-L.; Wu, J.; Wan, L.-S.; Xu, Z.-K. Cobalt-porphyrin/dansyl piperazine complex coated filter paper for "turn on" fluorescence sensing of ammonia gas. RSC Adv. 2015, 5, 99361-99363. [CrossRef]

42. Gan, L.H.; Roshan Deen, G.; Gan, Y.Y.; Tam, K.C. Water sorption studies of new pH-responsive $\mathrm{N}$-acryloyl-N'-methyl piperazine and methyl methacrylate hydrogels. Eur. Polym. J. 2001, 37, 1473-1478. [CrossRef]

43. Mah, C.H.; Wu, Q.Y.; Deen, G.R. Effect of nature of chemical crosslinker on swelling and solubility parameter of a new stimuli-responsive cationic poly (N-acryloyl-N'-propyl piperazine) hydrogel. Polym. Bull. 2018, 75, 221-238. [CrossRef]

44. Xu, M.-J.; Ma, K.; Liu, C.; Li, B. Synthesis of the poly(phosphoric-boric acid) piperazine and its application as an effective flame retardant for epoxy resins. Polym. Eng. Sci. 2018, 58, 1858-1867. [CrossRef]

45. Tan, Y.; Shao, Z.-B.; Yu, L.-X.; Long, J.-W.; Qi, M.; Chen, L.; Wang, Y.-Z. Piperazine-modified ammonium polyphosphate as monocomponent flame-retardant hardener for epoxy resin: Flame retardance, curing behavior and mechanical property. Polym. Chem. 2016, 7, 3003-3012. [CrossRef]

46. Ousslim, A.; Chetouani, A.; Hammouti, B.; Bekkouch, K.; Al-Deyab, S.S.; Aouniti, A.; Elidrissi, A. Thermodynamics, quantum and electrochemical studies of corrosion of iron by piperazine compounds in sulphuric acid. Int. J. Electrochem. Sci. 2013, 8, 5980-6004.

47. Mondal, S.K.; Taylor, S.R. The identification and characterization of organic corrosion inhibitors: Correlation of a computational model with experimental results. J. Electrochem. Soc. 2014, 161, C476-C485. [CrossRef]

48. Nnaji, N.J.N.; Ujam, O.T.; Ibisi, N.E.; Ani, J.U.; Onuegbu, T.O.; Olasunkanmi, L.O.; Ebenso, E.E. Morpholine and piperazine based carboxamide derivatives as corrosion inhibitors of mild steel in $\mathrm{HCl}$ medium. J. Mol. Liq. 2017, 230, 652-661. [CrossRef]

49. Jorcin, J.-B.; Aragon, E.; Merlatti, C.; Pébère, N. Delaminated areas beneath organic coating: A local electrochemical impedance approach. Corros. Sci. 2006, 48, 1779-1790. [CrossRef]

50. Jimenez-Morales, A.; Galván, J.C.; Aranda, P.; Ruiz-Hitzky, E. Hybrid organic-inorganic electrode-membranes based on organo- polysiloxane/macrocycle systems. Mater. Res. Soc. Symp. Proc. 1998, 519, 211-216. [CrossRef]

51. El Hadad, A.A.; Carbonell, D.; Barranco, V.; Jiménez-Morales, A.; Casal, B.; Galván, J.C. Preparation of sol-gel hybrid materials from $\gamma$-methacryloxypropyltrimethoxysilane and tetramethyl orthosilicate: Study of the hydrolysis and condensation reactions. Colloid Polym. Sci. 2011, 289, 1875-1883. [CrossRef] 
52. Aranda, P.; Jiménez-Morales, A.; Galván, J.C.; Casal, B.; Ruiz-Hitzky, E. Composite membranes based on macrocycle/polysiloxanes: Preparation, characterization and electrochemical behavior. J. Mat. Chem. 1995, 5, 817-826. [CrossRef]

53. Criado, M.; Sobrados, I.; Sanz, J. Polymerization of hybrid organic-inorganic materials from several silicon compounds followed by TGA/DTA, FTIR and NMR techniques. Prog. Org. Coat. 2014, 77, 880-891. [CrossRef]

54. Fardjaoui, N.-E.-H.; Wicklein, B.; Aranda, P.; Sobrados, I.; El Berrichi, F.Z.; Ruiz-Hitzky, E. Modulation of inorganic matrices for functional nanoarchitectures fabrication: The simultaneous effect of moisture and temperature in the preparation of metakaolin based geopolymers. Bull. Chem. Soc. Jpn. 2018, 91, 1158-1167. [CrossRef]

55. Lino, A.M.; Gehlen, M.H. Styryl dye formation promoted by catalytic centers of piperazine bound to a silica surface traced by single molecule fluorescence microscopy. Phys. Chem. Chem. Phys. 2017, 19, 20984-20990. [CrossRef] [PubMed]

56. Beaunier, L.; Epelboin, I.; Lestrade, J.C.; Takenouti, H. Etude electrochimique, et par microscopie electronique a balayage, du fer recouvert de peinture. Surf. Technol. 1976, 4, 237-254. [CrossRef]

57. Walter, G.W. A review of impedance plot methods used for corrosion performance analysis of painted metals. Corr. Sci. 1986, 26, 681-703. [CrossRef]

58. Feliu, S.; Galván, J.C.; Morcillo, M. An interpretation of electrical impedance diagrams for painted galvanized steel. Prog. Org. Coat. 1989, 17, 143-153. [CrossRef]

59. Chimenti, S.; Vega, J.M.; Aguirre, M.; García-Lecina, E.; Díez, J.A.; Grande, H.-J.; Paulis, M.; Leiza, J.R. Effective incorporation of $\mathrm{ZnO}$ nanoparticles by miniemulsion polymerization in waterborne binders for steel corrosion protection. J. Coat. Technol. Res. 2017, 14, 829-1839. [CrossRef]

60. Koochaki, M.S.; Nouri Khorasani, S.; Esmaeely Neisiany, R.; Ashrafi, A.; Magni, M.; Trasatti, S.P. Facile strategy toward the development of a self-healing coating by electrospray method. Mater. Res. Express 2019, 6, 116444. [CrossRef]

61. Amand, S.; Musiani, M.; Orazem, M.E.; Pébère, N.; Tribollet, B.; Vivier, V. Constant-phase-element behavior caused by inhomogeneous water uptake in anti-corrosion coatings. Electrochim. Acta 2013, 87, 693-700. [CrossRef]

62. Musiani, M.; Orazem, M.E.; Pébère, N.; Tribollet, B.; Vivier, V. Determination of resistivity profiles in anti-corrosion coatings from constant-phase-element parameters. Prog. Org. Coat. 2014, 77, 2076-2083. [CrossRef]

63. Jorcin, J.-B.; Orazem, M.E.; Pébère, N.; Tribollet, B.; Tribollet, B. CPE analysis by local electrochemical impedance spectroscopy. Electrochim. Acta 2006, 51, 1473-1479. [CrossRef]

64. Hsu, C.H.; Mansfeld, F. Concernng the conversion of the constant phase element parameter Y0 into a capacitance. Corrosion 2001, 57, 747-748. [CrossRef]

65. Musiani, M.; Orazem, M.E.; Pébère, N.; Tribollet, B.; Vivier, V. Constant-phase-element behavior caused by coupled resistivity and permittivity distributions in films. J. Electrochem. Soc. 2011, 158, C424-C428. [CrossRef]

66. Van Westing, E.P.M.; Ferrari, G.M.; De Wit, J.H.W. The determination of coating performance with impedance measurements-II. Water uptake of coatings. Corros. Sci. 1994, 36, 957-977. [CrossRef]

67. Gharbi, O.; Ngo, K.; Turmine, M.; Vivier, V. Local electrochemical impedance spectroscopy: A window into heterogeneous interfaces. Curr. Opin. Electrochem. 2020, 20, 1-7. [CrossRef]

68. Barranco, V.; Carmona, N.; Galván, J.C.; Grobelny, M.; Kwiatkowski, L.; Villegas, M.A. Electrochemical study of tailored sol-gel thin films as pre-treatment prior to organic coating for AZ91 magnesium alloy. Prog. Org. Coat. 2010, 68, 347-355. [CrossRef]

69. Huang, V.M.; Wu, S.-L.; Orazem, M.E.; Pébre, N.; Tribollet, B.; Vivier, V. Local electrochemical impedance spectroscopy: A review and some recent developments. Electrochim. Acta 2011, 56, 8048-8057. [CrossRef]

70. Montoya, R.; García-Galván, F.R.; Jiménez-Morales, A.; Galván, J.C. Effect of conductivity and frequency on detection of heterogeneities in solid/liquid interfaces using local electrochemical impedance: Theoretical and experimental study. Electrochem. Commun. 2012, 15, 5-9. [CrossRef]

(C) 2020 by the authors. Licensee MDPI, Basel, Switzerland. This article is an open access article distributed under the terms and conditions of the Creative Commons Attribution (CC BY) license (http://creativecommons.org/licenses/by/4.0/). 